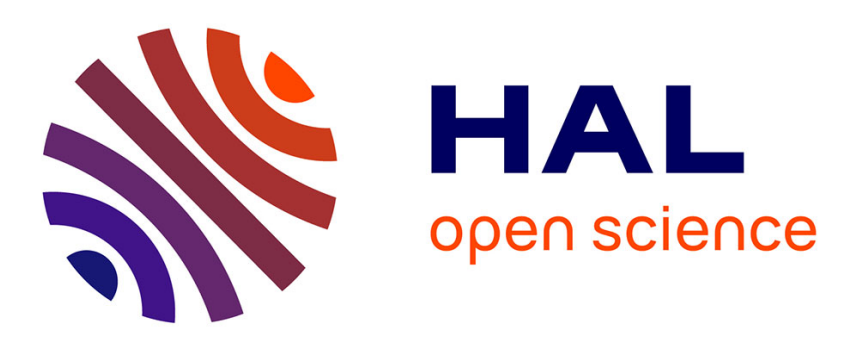

\title{
Electrochemical Reactivity and Design of NiP2 Negative Electrodes for Secondary Li-Ion Batteries
}

Frédéric Gillot, Simeon Boyanov, Loic Dupont, Marie-Liesse Doublet, Mathieu Morcrette, Laure Monconduit, Jean-marie Tarascon

\section{- To cite this version:}

Frédéric Gillot, Simeon Boyanov, Loic Dupont, Marie-Liesse Doublet, Mathieu Morcrette, et al.. Electrochemical Reactivity and Design of NiP2 Negative Electrodes for Secondary Li-Ion Batteries. Chemistry of Materials, 2005, 17 (25), pp.6327-6337. 10.1021/cm051574b . hal-00383231

\section{HAL Id: hal-00383231 https://hal.science/hal-00383231}

Submitted on 12 May 2009

HAL is a multi-disciplinary open access archive for the deposit and dissemination of scientific research documents, whether they are published or not. The documents may come from teaching and research institutions in France or abroad, or from public or private research centers.
L'archive ouverte pluridisciplinaire $\mathbf{H A L}$, est destinée au dépôt et à la diffusion de documents scientifiques de niveau recherche, publiés ou non, émanant des établissements d'enseignement et de recherche français ou étrangers, des laboratoires publics ou privés. 


\title{
On the electrochemical reactivity and design of $\mathrm{NiP}_{2}$
} negative electrodes for secondary Li-ion batteries

\author{
F. Gillot ${ }^{(a)}$, S. Boyanov ${ }^{(b)}$, L. Dupont ${ }^{(a)}$, M-L. Doublet ${ }^{(c)}$,

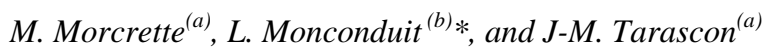

(a) LRCS -UMR 6007- Université de Picardie Jules Verne, 80039 Amiens, France

(b) LAMMI -UMR 5072 - Université Montpellier II, 34095 Montpellier

(c) LSDSMS -UMR 5636 - Université Montpellier II, 34095 Montpellier 
We report the electrochemical study of cubic and monoclinic $\mathrm{NiP}_{2}$ polymorphs towards $\mathrm{Li}$, as candidate for anodic applications for Li-ion batteries. We found that the monoclinic form is the most attractive one performance-wise. Monoclinic $\mathrm{NiP}_{2}$ can reversibly uptake 5 lithium per formula unit leading to reversible capacities of $1000 \mathrm{mAh} / \mathrm{g}$ at an average potential of $0.9 \mathrm{~V} \mathrm{vs} \mathrm{Li}^{+} / \mathrm{Li}^{\circ}$. From complementary XRD and HREM measurements it was shown that during the first discharge the cubic phase undergoes a pure conversion process $\left(\mathrm{NiP}_{2}+6 \mathrm{Li}^{+}+6 \mathrm{e}^{-} \rightarrow \mathrm{Ni}^{\circ}+2 \mathrm{Li}_{3} \mathrm{P}\right)$ as opposed to a sequential insertionconversion process for monoclinic $\mathrm{NiP}_{2}$. Such a different behaviour rooted in subtle structural changes was explained through electronic structure calculations. Once the first discharged is achieved, both phases were shown to react with Li through a classical conversion process. More importantly, we report a novel way to design $\mathrm{NiP}_{2}$ electrodes with enhanced capacity retention and rate capabilities. It consists in growing the monoclinic $\mathrm{NiP}_{2}$ phase, through a vapour phase transport process, on a commercial Nifoam commonly used in Ni-based alkaline batteries. These new self-supported electrodes, based on chemically made interfaces, offer new opportunities to fully exploit the capacity gains provided by conversion reactions.

Corresponding author: moncondu@univ-montp2.fr

Keywords: Lithium ion batteries, nickel diphosphides, ball milling, ceramic, capacity retention

1. Introduction 
Fifteen years after their first commercialisation, rechargeable Li-ion batteries are widely accepted, and are becoming the main power source in today's portable electronics. They are even considered as serious candidates to power future hybrid electric vehicles (HEVs) and in the long run, EVs. Due to its advent on the market, such technology has been using a layered oxide $\left(\mathrm{LiCoO}_{2}\right)$ as positive electrode and a carbonaceous material as negative electrode, both reacting towards Li through insertion/deinsertion reactions. Improvements capacity-wise and energy-wise were rather the results of engineering than chemistry advances. The latter is low owing to the difficulty encountered in designing either positive materials that can react with more than one Li per $3 d$-metal or negative electrodes showing greater capacities than graphite while maintaining an excellent capacity retention. Driven by EV market demands, namely in terms of volume restriction, researchers have focused their attention on the search for either (i) high voltage redox systems (e.g., highly oxidant positive electrode materials) so that fewer cells will be required for a predefined application voltage, or (ii) high energy density systems by increasing the volumetric capacity of either the positive or negative electrode in order to reduce the size of each cell and therefore of the overall stack. Regarding negative electrodes, the most promising candidates have long been the metal elements capable of forming alloys with $\mathrm{Li}$, such as Si (4200 $\mathrm{mAh} / \mathrm{g}){ }^{[1]}$ or Sn $(1200 \mathrm{mAh} / \mathrm{g}) .{ }^{[2]}$ Owing to the poor efficiency of the Li alloying/de-alloying process leading to poor long-term stability, none of these electrodes had been used in practical cells yet. Such a long lasting limitation is at the verge of being overcome in light of some recent reports on Si embedded nanoparticles electrodes ${ }^{[3]}$ and SONY's recent announcement regarding the launching of NEXELION that uses a Sn-based nanocomposite negative electrode. ${ }^{[4]}$

Five years ago, searching for the benefits that nanomaterials could bring to the field of electrode materials, it was with great surprise that we unravelled that simple oxides can electrochemically react towards $\mathrm{Li}$ leading to sustainable reversible capacities as high as $900 \mathrm{mAh} / \mathrm{g}{ }^{[5]}$ These results were explained by the following conversion reaction: $\mathrm{M}_{\mathrm{x}} \mathrm{O}_{\mathrm{y}}+2 \mathrm{y} \mathrm{e}^{-}+2 \mathrm{y} \mathrm{Li}^{+} \leftrightarrows \mathrm{x} \mathrm{M}^{0}+\mathrm{y} \mathrm{Li}{ }_{2} \mathrm{O}$. It was later on demonstrated that this new Li reactivity mechanism was not specific to oxides but could also be 
found with sulphides, nitrides, fluorides, and phosphides. ${ }^{[6-9]}$ As compared to the classical insertion reactions that govern the energy stocked in the actual Li-ion batteries, and which are limited to $1 \mathrm{e}^{-}$even $0.5 \mathrm{e}^{-}$per $3 d$ metal atom $\left(\mathrm{LiCoO}_{2}\right)$, these new conversion reactions that can involve $2 \mathrm{e}^{-}$, or more, $($per $3 d$ metal atom), were thought of as a new means to enable the creation of a new class of electrodes with staggering capacity gains over various voltage ranges depending on the nature of the $\mathrm{X}$ anion.

Therefore, as research on these new electrodes proceeded, we rapidly experienced that if we ever wanted to fully utilize conversion reactions in practical cells, we needed to 1) enhance their poor kinetics that result in a large polarization, hence a poor energy efficiency, 2) improve their capacity retention upon cycling, and 3) find chemical ways to lower and narrow their voltage reactivity range towards Li. A few of these challenges have already been successfully addressed. Kinetics improvements of conversion reactions together with enhancement of their capacity retention were achieved by either 1) acting at the particle surfaces through the use of conducting coatings as reported by Li et al. for carboncoated $\mathrm{Cr}_{2} \mathrm{O}_{3}$ particles, ${ }^{[10]}$ 2) moving from bulk to thin film material as illustrated by the studies by Pralong et al. on $\mathrm{Co}_{3} \mathrm{O}_{4}$ thin films, ${ }^{[11]}$ or 3) playing with new electrode design. For instance, we recently reported on a new electrode configuration that consists in the high temperature growth of an electrochemical oxide layer at the surface of a stainless steel current collector. Owing to this chemically made current collector/active material interface, the electrode shows an outstanding capacity retention (> 800 cycles) and good kinetics (90\% of the full capacity at 1C). Therefore, such electrodes still suffer from a large polarisation $(\cong 0.8 \mathrm{~V})$ that is intrinsic to conversion reactions and linked, among others, to the electrical energy needed to overcome the energetic barrier. The latter is associated to the reversible breaking/formation of chemical M-X bonds as well as to the electronic and ionic conducting properties of the precursors $\mathrm{M}_{\mathrm{x}} \mathrm{X}_{\mathrm{y}}$ and generated Li-based ternary phases. From a literature survey of the entire conversion reactions so far reported ${ }^{[12]}$ for whatever fluorides, oxides, sulphides, or phosphides coupled with our own experimental investigation, it turns out that the polarization $\Delta \mathrm{V}$ is decreasing as we move from fluorides $(\Delta \mathrm{V} \cong 1.1 \mathrm{~V})$ to oxides $(\Delta \mathrm{V} \cong 0.9 \mathrm{~V})$, sulphides $(\Delta \mathrm{V} \cong 0.7 \mathrm{~V})$ and phosphides $(\Delta \mathrm{V} \cong 0.4$ V). This is fully consistent with the decrease in the M-X bond polarization from M-F to M-P. Therefore 
a particular interest comes from the phosphides that react with Li over a narrow potential range, as reported by different groups. For instance, $\mathrm{FeP}_{2}{ }^{[13]}$ and $\mathrm{CoP}_{3}{ }^{[14]}$ reversibly react with $\mathrm{Li}$ at an average voltage of $1 \mathrm{~V}$ and show flat charge and discharge curves separated by about $0.4-0.5 \mathrm{~V}$. However, their cycling performances were claimed to be very poor. More recently Ti-P compounds, synthesized by the ball milling method, were shown to present a capacity of about $900 \mathrm{mAh} / \mathrm{g}$ retained after 10 cycles. ${ }^{[15]}$ Owing to the positive attributes of phosphides compared to oxides, except for the capacity retention, we decided to carry out a full electrochemical study of the binary $\mathrm{M}_{\mathrm{x}} \mathrm{P}_{\mathrm{y}}$ phosphides family as reported herein. Through this exploratory survey of the 3d-metal phosphides, the $\mathrm{NiP}_{2}$ phase, which can crystallize either in a cubic or in a monoclinic form and which can be grown on a Ni-foam current collector, turns out to be quite an attractive negative material. The paper is organized as follows. An experimental section describes the synthesis and chemical/physical characterizations of $\mathrm{NiP}_{2}$. Section 2 describes its electrochemical performance together with attempts at determining the reactivity mechanism as deduced by in situ X-ray, HRTEM measurements and electronic structure calculations. Finally, the design of a self-supported $\mathrm{NiP}_{2}$ electrode for long cyclability application is reported as an improvement.

\section{Experimental Section}

\section{$X R D, T E M$ and SEM}

X-ray diffraction (XRD) measurements on powdered $\mathrm{NiP}_{2}$ samples were performed on a Philips Xpert diffractometer using the $\mathrm{CuK}_{\alpha 1}$ monochromatic radiation. A specifically modified scanning electron microscope Philips field effect gun (FEG) XL-30, as previously reported, ${ }^{[16]}$ was used to carry out SEM studies on either Li-free or partially lithiated samples. Tecnai F20 ST transmission electron microscope equipped with EDS analysis was used to conduct our TEM/HRTEM investigations. To perform these experiments, the cells were stopped and opened in a dry box once cycled down to the required voltage. 
The partially lithiated material was recovered and washed with dimethyl carbonate (DMC) prior to being placed onto a copper grid mounted on our TEM sample holder. Through a special mobile airlock of our own design, the sample was then transferred to the TEM, without any air exposure, for selectedarea electron diffraction (SAED) pattern and bright field image collection.

\section{Electrochemical tests}

Swagelok-type cells were assembled in an argon filled glove box and cycled using a VMP or a Mac Pile automatic cycling/data recording system (Biologic Co, Claix, France) in a potential window between $2.5-2$ and $0.02 \mathrm{~V}$ vs. $\mathrm{Li}^{+} / \mathrm{Li}^{0}$ and a cycling rate of $\mathrm{C} / 10$ (that is one lithium per formula unit in 10 hours). These cells comprise a Li metal disc as the negative electrode, a Whatman GF/D borosilicate glass fiber sheet saturated with a $1 \mathrm{M} \mathrm{LiPF}_{6}$ in ethylene carbonate (EC), dimethyl carbonate (DMC) (1:1 in weight) as the electrolyte, and unless otherwise specified a positive electrode made by mixing the starting transition metal phosphides powder with 15\% (weighed) carbon black (SP). Usually, 10 to 12 $\mathrm{mg}$ of the mixed powders was placed on top of the Swagelok plunger.

In situ XRD electrochemical cells assembled similarly to our Swagelok cell but with a beryllium window as current collector on the $\mathrm{RX}$ side were placed on a Brucker D8 diffractometer $\left(\mathrm{CoK}_{\alpha}=\right.$ $1.79026 \AA$ ) equipped with a PSD detector, and connected to the VMP system. The cell was discharged at a $\mathrm{C} / 10$ rate and the $\mathrm{X}$-ray powder patterns were collected for every 0.1 reacted $\mathrm{Li}$.

Electronic structure calculations were performed using both the extended Hückel tight-binding (EHTB) method and the first-principle density functional theory (DFT) using CAESAR ${ }^{[17]}$ and VASP

${ }^{[18]}$ codes, respectively. The former is used to give a qualitative picture of the molecular $\mathrm{M}_{\mathrm{x}} \mathrm{P}_{\mathrm{y}}$ electronic structures whereas the latter allows full structural relaxations and free electronic energy calculations.

\section{Results}




\section{Synthesis}

The monoclinic $\mathrm{NiP}_{2}$ phase was synthesized at high temperature by placing stoichiometric amounts of nickel metal (Ni Alfa Aesar, 350 mesh, 99.9\%) and red phosphorous (P Alfa Aesar, 100 mesh, 99\%) powders in a sealed evacuated silica ampoule. ${ }^{[19]}$ The ampoule was placed into a furnace, whose temperature was increased to $900^{\circ} \mathrm{C}$ using a ramp of $20^{\circ} \mathrm{C} / \mathrm{h}$, and held to this temperature for 5 days. The samples (denoted hereafter HT) were air-quenched.

Although the cubic $\mathrm{NiP}_{2}$ phase was originally prepared at high pressure, ${ }^{[20]}$ we succeeded in synthesizing it by room temperature ball milling (BM) with a Spex 8000 mixer-mill, as previously reported. ${ }^{[21]}$ To prepare $1 \mathrm{~g}$ of $\mathrm{NiP}_{2}$, stoichiometric amounts of $\mathrm{Ni}$ metal and red phosphorous powders were placed into a stainless steel container together with steel balls so that the powder to ball weight ratio ranged from 8:1 to $10: 1$. Through a survey of various grinding times we experienced that the optimal ball milling time to obtain single-phase powders was 8 hours.

The XRD patterns of $\mathrm{NiP}_{2}-\mathrm{HT}$ and $\mathrm{NiP}_{2}-\mathrm{BM}$ powders are depicted Figs. 1 and 2. The results for $\mathrm{NiP}_{2}-\mathrm{HT}$ reveal sharp Bragg peaks, indicative of a highly crystalline sample, and which could all be indexed on the basis of a monoclinic cell with lattice parameters $(a=6.38 \AA, b=5.62 \AA, c=6.08 \AA$, $\beta=126.22, \mathrm{C} 2 / \mathrm{c}$ ) similar to those reported in the literature. ${ }^{[19]}$ Within the $\mathrm{NiP}_{2}$ monoclinic unit cell, Ni is simply coordinated by $\mathrm{P}$ atoms in a nearly square-planar configuration. The structure can be viewed (right inset of Fig. 1) as sheets of warped edge-sharing $\mathrm{NiP}_{4}$ square-planes, connected to each other through short P-P distances at $2.22 \AA$. A high degree of covalence is expected for the four Ni-P bonds of the square.

For the $\mathrm{NiP}_{2}-\mathrm{BM}$ sample, the XRD powder pattern reveals weak Bragg peaks indicative of a poorly crystallized powder (Fig 2). All peaks are indexed in the Pa-3 (205) space group with a= $5.4706 \AA$ cell parameter. ${ }^{[20]}$ This pyrite-type $\mathrm{NiP}_{2}$ phase is usually prepared by high-pressure technique. The occurrence of this structure in the Ni dipnictides and its absence in the others $(\mathrm{Fe}, \mathrm{Cu}, \mathrm{Pd})$ has been

explained in terms of electronic stability as derived from band structure calculations. ${ }^{[20]}$ Within the $\mathrm{NiP}_{2}$ 
pyrite-type structure the nickel atoms are in a trigonal distorted octahedron surrounded by $\mathrm{P}$ atoms. The $\mathrm{P}$ atoms are in the form of a di-anion that has the formal valence $\mathrm{P}_{2}{ }^{4-}$. The P-P distance is smaller than the sum of the normal tetrahedral covalent radii (1.10 $\AA$, Pauling). The Ni-P distance is $2.29 \AA$ and the octahedral covalent radius of nickel is $1.23 \AA$.

Powder morphologies were investigated by SEM (left insets of Figs. 1 and 2). In both cases the powders are made of shapeless particles having an average size ranging from 5 to $50 \mu \mathrm{m}$ for the $\mathrm{NiP}_{2^{-}}$ HT sample and from 0.5 to $2 \mu \mathrm{m}$ for the ball milled $\mathrm{NiP}_{2}$-BM sample. Both samples were highly conductive consistent with their previously reported metallic behaviour. ${ }^{[22]}$

\section{Electrochemical properties}

Two $\mathrm{Li} / \mathrm{NiP}_{2}-\mathrm{HT}$ and $\mathrm{Li} / \mathrm{NiP}_{2}-\mathrm{BM}$ half-cells were assembled and tested for their electrochemical behaviour at a $\mathrm{C} / 10$ rate. During the first discharge down to $0 \mathrm{~V}$, the voltage composition curves for $\mathrm{NiP}_{2}$-HT (Fig. 3) and $\mathrm{NiP}_{2}$-BM (Fig. 4) -based Li cells show the insertion of 5.9 and $5.0 \mathrm{Li}^{+}$per formula unit, respectively. Upon recharge up to $2 \mathrm{~V}$ and $2.5 \mathrm{~V}$, only $5.0 \mathrm{Li}^{+}$per formula unit can be removed from $\mathrm{NiP}_{2}$-HT and $4.2 \mathrm{Li}^{+}$from $\mathrm{NiP}_{2}-\mathrm{BM}$ leading to reversible capacities of $1000 \mathrm{mAh} / \mathrm{g}(4900$ $\left.\mathrm{mAh} / \mathrm{cm}^{3}\right)$ and $840 \mathrm{mAh} / \mathrm{g}\left(4100 \mathrm{mAh} / \mathrm{cm}^{3}\right)$, respectively. Both cells show around $16 \%$ capacity loss between the first discharge and the first charge and a capacity decay upon cycling that is worse for the $\mathrm{Li} / \mathrm{NiP}_{2}-\mathrm{BM}$ cell at a $\mathrm{C} / 10$ rate and pretty much the same at a $\mathrm{C} / 20$ (inset Fig. 4). Therefore, the most striking difference between the two cells lies in the shape of the first discharge curve. For the $\mathrm{Li} / \mathrm{NiP}_{2}-$ $\mathrm{BM}$ cell, after an initial Li uptake associated to the insertion of Li into the acetylene black, the voltage continuously and smoothly decreases down to zero volt, as often observed in ball-milled electrodes. This is deeply contrasted with the discharge profile of the $\mathrm{Li} / \mathrm{NiP}_{2}-\mathrm{HT}$ cell that, besides the voltage hint associated to acetylene black, shows a well pronounced voltage step near $\mathrm{x}=2.4$ that vanishes upon the subsequent discharges. Interestingly, except for the first discharge, both cells present the same charge/discharge voltage profiles upon subsequent cycles. The difference in the first discharge profile 
between $\mathrm{Li} / \mathrm{NiP}_{2}-\mathrm{HT}$ and $\mathrm{Li} / \mathrm{NiP}_{2}-\mathrm{BM}$ cells suggests a different Li-reactivity mechanism, clearly linked to the different structural arrangements of both starting electrodes. To get deeper insights into these differences, both in situ XRD measurements and semi in situ high-resolution transmission electron studies were performed.

\section{In situ X-ray Diffraction}

As $\mathrm{NiP}_{2}-\mathrm{HT} / \mathrm{Li}$ cell is discharged (Fig. 5), we initially observed a continuous decrease in the intensity of the main $\mathrm{NiP}_{2}-\mathrm{HT}$ Bragg peaks to the expense of a new set of Bragg peaks illustrated by stars on Fig. 5. These peaks then grow upon increasing $x$ to become unique at $x=2.4$, indicative of a new phase denoted A having the following formula $\mathrm{Li}_{2.4} \mathrm{NiP}_{2}$ and whose structure will be discussed below. Pursuing the lithiation results in the disappearance of the A-phase to the expense of a new set of broad peaks illustrated by circles on Fig. 5 and corresponding to the hexagonal $\mathrm{Li}_{3} \mathrm{P} .{ }^{[23]}$

In contrast, when $\mathrm{NiP}_{2}-\mathrm{BM} / \mathrm{Li}$ is discharged, we only observe (Fig. 6) a continuous decrease in the $\mathrm{NiP}_{2}-\mathrm{BM}$ main Bragg peaks up to $\mathrm{x}=4.5$ with the appearance of broad peaks located at the $\mathrm{Li}_{3} \mathrm{P}$ characteristic angles at the end of the reduction process.

When the two different cells are charged, similar XRD patterns are obtained for $\mathrm{NiP}_{2}-\mathrm{HT}$ and $\mathrm{NiP}_{2}-$ BM. They are shown for the $\mathrm{NiP}_{2}-\mathrm{BM}$ on Fig. 7 (a). They first show a progressive decrease in the $\mathrm{Li}_{3} \mathrm{P}$ Bragg peaks, and a complete disappearance down to $\mathrm{x} \approx 2$. The X-ray powder patterns for the fully charged samples show a broad and diffuse peak, characteristic of an amorphous electrode.

Upon subsequent cycles, both in situ X-ray cells show similar behaviours with namely the direct growth of $\mathrm{Li}_{3} \mathrm{P}$ during discharge (presented here for $\mathrm{NiP}_{2}-\mathrm{BM}$ Fig. $7 \mathrm{~b}$ ) and its disappearance during charge. At first sight, this is indicative of a conversion reaction process $\left(\mathrm{NiP}_{2}+6 \mathrm{Li}^{+}+6 \mathrm{e}^{-} \rightarrow 2 \mathrm{Li}_{3} \mathrm{P}+\right.$ Ni). Note that, in both cases, we could not spot any signs of Bragg peaks corresponding to the growth of metallic Ni. According to the in situ X-ray data, the formulation of the fully discharged composite electrode should be identical independently of whether we have discharged a $\mathrm{NiP}_{2}-\mathrm{HT} / \mathrm{Li}$ or a $\mathrm{NiP}_{2}$ - 
$\mathrm{BM} / \mathrm{Li}$ cell. Owing to such a similarity, the cells should then behave alike without showing any differences in capacity retention. At first glance, it would be tempting to explain this phenomenon in terms of powder morphology differences between the two samples. However, we can not rule out volume consideration arguments to account for such a different capacity retention behaviour owing to the fact that the unit cell volume of $\mathrm{NiP}_{2}-\mathrm{BM}$ cubic cell is about $12 \AA^{3}$ lower than that of the $\mathrm{NiP}_{2}-\mathrm{HT}$ monoclinic cell.

While the in situ X-ray data enabled to pin down differences between the Li-reactivity mechanism of $\mathrm{NiP}_{2}-\mathrm{HT}$ and $\mathrm{NiP}_{2}-\mathrm{BM}$, with namely a hint of an insertion process followed by a conversion process for the former as compared to a single conversion process for the latter, it did not allow to solve the structure of the A-phase and failed to identify Ni particles expected for the conventional conversion reaction. An HRTEM study was undertaken in order to check the presence of $\mathrm{Ni}$ in the fully discharged samples and to provide a structural assessment for the A-phase.

\section{HRTEM study}

The monoclinic $\mathrm{NiP}_{2}$ power is made of large ceramic particles having sharp edges and being a few microns long. High resolution TEM image (Fig. 8) taken along the 001 zone axis (left inset) on a particle edge (right inset) shows that the particles are pretty well crystallized with no obvious fault. EDS analyses were performed on this sample in order to standardize the nickel/phosphorous ratio.

To identify the intermediary A-phase, a $\mathrm{NiP}_{2}-\mathrm{HT} / \mathrm{Li}$ cell was discharged down to $\mathrm{x}=2.5$ and once recovered the (" $\mathrm{Li}_{2.5} \mathrm{NiP}_{2}$ ") electrode was examined by TEM. While a random intergrowth between two phases was first suspected on the bright field images (not shown), the high resolution image taken at the interface between two regions (Fig. 9a) showed that the second phase does not exist from a crystallographic point of view but is the result of stacking faults piling up between two consecutive well crystallized regions. The corresponding SAED pattern (Fig. 9b) confirms this observation since well 
defined spots induced by a well crystallized phase as well as diffuse lines resulting from stacking faults are observed.

An electron diffraction study was carried out to determine the cell parameters of the phase responsible for the crystallized regions. From the set of dots recorded on several SAED patterns from the same crystal and from several particles, we succeeded in building the reciprocal space (Fig. 9c). A tetragonal cell could then be proposed as a rough estimate: $\mathrm{a}=5.5 \AA, \mathrm{c}=4.2 \AA$. Such a cell can be easily deduced from the initial monoclinic $\mathrm{NiP}_{2}-\mathrm{HT}$ cell. As shown on Fig. 10a, Li insertion in the inter-layers region should lead to the breaking of the short P-P bridges, favouring an easy gliding of all adjacent sheets and therefore a closing of the monoclinic $\beta$ angle. This could explain the nearly orthogonal angle found for the tetragonal cell. Simultaneously, a square planar to pseudo tetrahedral distortion occurs in the $\mathrm{NiP}_{4}$ entities to minimize the P-P repulsions induced by the exceeding charge on the phosphorous. This should disconnect the $\mathrm{NiP}_{4}$ square planes from each other in at least one direction, leading to $\mathrm{Ni}_{2} \mathrm{P}_{4}$ chains of edge-sharing distorted tetrahedra. This new linkage mode is not only necessary to compensate the lack of P-atoms induced by the in-plane re-arrangement, but appears also to be the most plausible local distortion to explain the unit cell parameters measured from HRTEM. In this novel lamellar packing, one can easily link the periodic $\mathrm{Ni}-\mathrm{Ni}$ distances to the translation vectors of the pseudo tetragonal phase, i.e. $\mathrm{a} \approx \mathrm{b}=5.5 \AA$ and $\mathrm{c}=4.2 \AA$. This picture is consistent with the electronic structure calculation performed on the $\mathrm{NiP}_{4}$ square plane given on Fig.10 c and showing that the phosphorous atoms are the redox centres in the $\mathrm{NiP}_{2}$ monoclinic structure. Indeed, the splitting of the metallic $3 d$ orbitals in the $\mathrm{D}_{4 \mathrm{~h}}$ local symmetry leads to four quasi-degenerated metallic-like orbitals well separated in energy from the fifth metallic orbital by several P-like levels. In such a configuration, the transition metal is $\mathrm{d}^{8}$ (i.e. $\mathrm{Ni}^{+\mathrm{II}}$ ) yielding the $\mathrm{Ni}^{+\mathrm{II}}\left(\mathrm{P}^{-}\right)_{2}$ general formulation. This is completely different from the $\mathrm{NiP}_{2}$ cubic structure in which the octahedral metallic environment leads to a $\mathrm{d}^{6}$ electronic configuration, i.e. a Ni ${ }^{+\mathrm{IV}}\left(\mathrm{P}^{2-}\right)_{2}$, and therefore to an obviously different redox mechanism (Fig. 10d).

To get a better insight in the structural aspects linked to the existence/growth of the " $\mathrm{Li}_{2.5} \mathrm{NiP}_{2}$ " phase, we further processed the recorded SAED patterns. In carrying out meticulous measurements, we 
realized that the "tetragonal cell" (used to index Figs. 9b-d) should not be considered as a real cell but rather as a sub-cell. Indeed, the 001 zone axis electron diffraction pattern (not shown here) shows that a and $\mathrm{b}$ cell parameters are slightly different while the $[1-30]^{*}$ zone axis SAED pattern (Fig.9 d) gives evidence of a monoclinic cell rather than a tetragonal one since the $[310]^{*}$ and $[001]^{*}$ directions are not perpendicular. We are currently investigating the $" \mathrm{Li}_{2.5} \mathrm{NiP}_{2}$ " monoclinic cell parameters by combining these results with recorded XRD patterns using pattern matching.

Returning to Fig. 9a, the coexistence of well crystallized domains parted from disordered ones is most likely the signature of local composition changes associated either to 1) difficulties encountered in reaching equilibrium during sample preparation or 2) to the advent of a second Li-driven reaction owing to the fact that we exceed values of $\mathrm{x}$ corresponding to the existence of the A phase. Based on the fact that the same observations were made on samples discharged up to $\mathrm{x}=2.2$ only and at rates as slow as $\mathrm{C} / 100$ led us to conclude that we are dealing with a highly unstable phase. Consequently, it is quite possible that, for $\mathrm{x}$ values close to the limit $\mathrm{x}$ value, there is a competition between the end of the $\mathrm{Li}$ insertion process and the beginning of the conversion reaction process as described hereunder. Evidence of such initiation of the conversion process was brought about by the spectacular collapse of the structure (Fig. 11) associated to the release of Ni particles (inset Fig. 11).

Moving to the end of the discharge process, agglomerates containing nanoparticles as well as a huge quantity of polymeric coating are observed (Fig. 12a inset). Owing to the rapid evaporation of the polymer coating under the beam, difficulties were encountered in initially collecting highly contrasted images (see Fig. 12a). Therefore, after a long time of exposure, crystallized $5 \mathrm{~nm}$ particles identified from the corresponding SAED pattern (inset Fig. 12b) as Ni particles are nicely observed (Fig. 12b). Contrary to the $\mathrm{XRD}$ results, $\mathrm{Li}_{3} \mathrm{P}$ reflections are not easily observed on the corresponding SAED patterns. Such a different behaviour could be nested in an enhanced solubility of the $\mathrm{Li}_{3} \mathrm{P}$ into the polymer electrolyte so that, when the polymer evaporates under beam exposure, it takes away a part of the $\mathrm{Li}_{3} \mathrm{P}$ leaving mainly nickel nanoparticles on the edge of the agglomerates where the TEM observation is done. 
Finally, bright field images of the fully recharged sample (cell cut-off voltage fixed to $2 \mathrm{~V}$ ) indicate that it is quite heterogeneous with agglomerates either surrounded by (Figs. 13a-b) or free from polymeric coating (Fig. 13c). High-resolution images (Fig. 13d) taken on these aggregates indicate that their cores are amorphous while their edges are crystallized (lattice fringes are observed on 5 to $10 \mathrm{~nm}$ wide domains). According to the fast Fourier transformation (FFT) calculated on the HRTEM images (inset Fig.13d), measured inter-reticular distances were assigned to 110,200 or $021 \mathrm{NiP}_{2}$ reflections. According to the electrochemical data, the process is nearly fully reversible therefore an intriguing question yet to be answered is why only part of the reformed $\mathrm{NiP}_{2}$ is crystallized?

Last, to throw some light on the electrochemical behaviour differences between the cells using either $\mathrm{NiP}_{2}-\mathrm{HT}$ or $\mathrm{NiP}_{2}-\mathrm{BM}$ as the positive electrode, our TEM study was extended to materials recovered from partially discharged/charged cubic $\mathrm{NiP}_{2}-\mathrm{BM} / \mathrm{Li}$ cells. TEM images collected for the fully discharged cubic $\mathrm{NiP}_{2}-\mathrm{BM}$ phase were similar to the ones observed for the fully lithiated monoclinic $\mathrm{NiP}_{2}$-HT. They show both the polymeric coating vanishing under the beam and the occurrence of nanoparticles. Therefore, in opposition to the previous case, the nanograins were amorphous and consequently could not clearly be assigned to metallic nickel. The fully charged cubic $\mathrm{NiP}_{2}-\mathrm{BM}$ sample (at $2.5 \mathrm{~V}$ ) is made as before of agglomerates of amorphous nanoparticles that neither high-resolution images nor SAED patterns could clearly identify.

\section{Discussion}

The above results show that both the monoclinic $\mathrm{NiP}_{2}-\mathrm{HT}$ and the cubic $\mathrm{NiP}_{2}-\mathrm{BM}$ phases behave similarly once the first discharge is fully achieved. $\mathrm{NiP}_{2}-\mathrm{HT}$ is reduced by Li through a two-step process enlisting first the insertion of $\mathrm{Li}$ into $\mathrm{NiP}_{2}$ to give a $\mathrm{Li}_{2.4} \mathrm{NiP}_{2}$ phase and secondly the conversion of $\mathrm{Li}_{2.4} \mathrm{NiP}_{2}$ into a composite made of $\mathrm{Li}_{3} \mathrm{P}$ and $\mathrm{Ni}^{\circ}$ nanoparticles. For $\mathrm{NiP}_{2}-\mathrm{BM}$, in contrast, a single reaction path was observed. Although no clear evidence of $\mathrm{Ni}^{\circ}$ nanoparticles was observed in the fully discharged sample, the direct conversion of $\mathrm{NiP}_{2}$ into $\mathrm{Li}_{3} \mathrm{P}$ and $\mathrm{Ni}^{\circ}$ is suggested. Usually, for the 
conversion reactions so far reported either with oxides, sulphides, fluorides, the measured amount of Li uptake during the first discharge was always greater than the theoretical one. The extra capacity was associated either to a reversible growth of an electrochemically gel-like polymer layer or to reversible heterogeneous interfacial storage mechanism. ${ }^{(24)}$ Presently, whatever the structure of the $\mathrm{NiP}_{2}$ precursor phase, the measured amount of Li uptake per formula unit (5.9 and 5 for monoclinic and cubic $\mathrm{NiP}_{2}$, respectively, carbon accounted) never reaches the value of 6 expected for the complete conversion reaction $\mathrm{NiP}_{2}+6 \mathrm{Li} \rightarrow 2 \mathrm{Li}_{3} \mathrm{P}+\mathrm{Ni}^{\circ}$ even though we gave evidence, as deduced from HREM, of the formation of a polymeric layer. This result came as a surprise, and as an attempt at rationalizing it, we checked the effect of the discharge cut-off voltage on the amount of Li uptake during the first discharge. Even by pushing the discharge down to voltages where we observed the onset of Li plating, we did not succeed in getting Li uptake values greater than 6.2 per formula unit. Although we don't have a sound straightforward explanation to account for the specific behaviour of phosphides towards conversion reactions we suppose that it has to do with the feasibility of having anionic redox centres as opposed to cationic redox centres only, as the other compounds we have so far investigated.

Another universal characteristic of the conversion reactions so far studied is the existence of a large potential difference between the first and second discharge, the latter being always a few 100ths of $\mathrm{mV}$ above. The larger drop in potential observed during the first discharge can be viewed as the necessary potential to provide the required activation energy to trigger the conversion reaction. Once this formation step is achieved, thanks to the nano character of the formed composite, the second discharge will be kinetically less limited and hence an increase of the discharge voltage. The phosphides are no exception to this phenomena since a $\Delta \mathrm{V}$ of $0.3 \mathrm{~V}$ and $0.5 \mathrm{~V}$ is observed between the first and second discharge for $\mathrm{NiP}_{2}-\mathrm{BM}$ and $\mathrm{NiP}_{2}-\mathrm{HT}$, respectively.

To explain the different mechanisms involved in the first discharge, first-principle electronic structure calculations have been performed on the cubic and the monoclinic $\mathrm{NiP}_{2}$ as well as on $\mathrm{Li}_{3} \mathrm{P}$ and $\mathrm{Ni}-\mathrm{metal}$. Very close free electronic energies are computed for the two fully relaxed systems, the cubic phase being thermodynamically more stable by no more than $25 \mathrm{meV}$ per unit cell than the monoclinic phase. 
These close energies would suggest equivalent equilibrium potentials for the $\mathrm{NiP}_{2}+6 \mathrm{Li} \rightarrow 2 \mathrm{Li}_{3} \mathrm{P}+\mathrm{Ni}^{\circ}$ conversion reaction, as corroborated by the enthalpy of reaction $(\Delta \mathrm{G})$ per Li atom computed for the two starting electrodes $\left(\Delta \mathrm{G}_{\text {mono }}=-0.897 \mathrm{eV}\right.$ and $\left.\Delta \mathrm{G}_{\mathrm{cub}}=-0.893 \mathrm{eV}\right)$. The different potentials observed in the first discharge voltage curves of $\mathrm{NiP}_{2}-\mathrm{HT}$ and $\mathrm{NiP}_{2}-\mathrm{BM}$ clearly correspond to different redox mechanisms associated with different $\mathrm{Ni}$ oxidation states and local environments. As shown by EHTB electronic structure calculations, the splitting of the metallic $3 d$-orbitals in the $\mathrm{D}_{4 \mathrm{~h}}$ (square-planar) and in the $\mathrm{Oh}$ (octahedral) symmetry induces a $\mathrm{Ni}^{+\mathrm{II}}\left(\mathrm{d}^{8}\right)$ and a Ni $\mathrm{i}^{+\mathrm{IV}}\left(\mathrm{d}^{6}\right)$ oxidation state, respectively. On one hand, the $\mathrm{NiP}_{2}$ cubic form can be easily deduced from the monoclinic form by a slight inter-layers contraction, consistent with the high-pressure synthetic conditions. On the other hand, the $\mathrm{NiP}_{2}$ monoclinic form can be deduced from the cubic form by a Jahn Teller-type distortion, easily consistent with a non-stable $\mathrm{d}^{8}$ octahedral environment. The closely packed structure of the cubic $\mathrm{NiP}_{2}$ prevents any lithium insertion, thus favouring a direct conversion reaction into $\mathrm{Li}_{3} \mathrm{P}$ and $\mathrm{Ni}^{\circ}$. In contrast, the monoclinic $\mathrm{NiP}_{2}$ exhibits some available inter-layers space to accommodate lithium ions, hence enabling the formation of the monoclinic " $\mathrm{Li}_{2.5} \mathrm{NiP}_{2}$ " phase. More precisely, if we accounted for the $\mathrm{Li}$ insertion into the SP-carbon added to the electrode, the stoichiometry of the monoclinic phase is near $\mathrm{Li}_{2} \mathrm{NiP}_{2}$

The break in the voltage-composition trace for $\mathrm{NiP}_{2}-\mathrm{HT} / \mathrm{Li}$ cells discharged at very low rates $(\mathrm{C} / 20)$ revealed the existence of the intercalated $\mathrm{Li}_{2} \mathrm{NiP}_{2}$. Therefore, by increasing the discharge rate to values approaching $\mathrm{C} / 5$, we observed a smoothing of the discharge curve. In light of such findings, a legitimate question is whether the absence of a step-voltage anomaly in the voltage-composition trace for $\mathrm{NiP}_{2}$ $\mathrm{BM} / \mathrm{Li}$ cells is simply the result of a poorly selected discharging rate. To check this point, we discharged a $\mathrm{NiP}_{2}-\mathrm{BM} / \mathrm{Li}$ cell at a $\mathrm{C} / 100$ rate and still observed a smooth voltage-composition trace providing an irrefutable proof that both $\mathrm{NiP}_{2}$ polymorphs react differently towards $\mathrm{Li}$.

Nevertheless, whatever the first discharge reacting paths for both cubic and monoclinic $\mathrm{NiP}_{2}$, we have shown, as deduced by HREM, that they are leading composition-wise to a somewhat identical fully discharged electrode material made of $\mathrm{Li}_{3} \mathrm{P}$ and $\mathrm{Ni}^{\circ}$ nanoparticules (the latter being amorphous for 
$\mathrm{NiP}_{2}-\mathrm{BM}$ and crystallized for $\left.\mathrm{NiP}_{2}-\mathrm{HT}\right)$. Once the first discharge is achieved, electrochemical data have further stressed the similarity between both $\mathrm{NiP}_{2}$ polymorphs owing to the superimposition of the voltage/composition traces or of their derivatives (Fig. 14) over the next charging/discharging cycles. Therefore, once the cycling is extensively pursued, such a similarity does not hold any longer since the capacity was shown to decay quite more rapidly for cubic-NiP $\mathrm{N}_{2}$ as compared to monoclinic- $\mathrm{NiP}_{2}$. Among the most common reasons to account for capacity decays upon cycling are (i) the presence of particles becoming electrically disconnected, (ii) the onset of secondary reactions enlisting either a slight instability of the phosphorous-based reaction products with the present electrolyte leading to some decomposition. Since electrolyte decomposition reactions catalyzed by electrode materials are known to be enhanced by defects and large surface areas, one would expect these reactions to be more pronounced for the $\mathrm{NiP}_{2}-\mathrm{BM}$ powders that are of poor crystalline nature and highly divided as compared to the bulky and highly crystalline $\mathrm{NiP}_{2}$-HT powders. On that basis, the largest capacity fading observed for the ball-milled $\mathrm{NiP}_{2}$ powders does not come as surprise.

Although, the capacity retention is $\mathrm{NiP}_{2}-\mathrm{HT}$ is better, it still fall short to be suitable for practical applications. Besides, both polymorphs show limited rate capabilities since only $60 \%$ of the initial capacity can be recovered as a $\mathrm{C}$ rate. Such negative aspects should therefore not overshadow the main attributes of binary phosphides over binary oxides for conversion reactions that are (i) a considerably lower polarization between charge and discharge voltage upon cycling $(0.4 \mathrm{~V}$ instead of $0.8 \mathrm{~V})$ leading to a better cycling efficiency and (ii) their lower irreversibility loss during the first cycle (15-to $16 \%$ as compared to the $25-30 \%$ for the oxides) and (iii) a high reversible capacity $(1000 \mathrm{mAh} / \mathrm{g}$ ) at an average potential close to $1 \mathrm{~V}$, which is high enough to avoid Li plating and low enough to penalize the output not too much voltage.

Based on our experience cumulated on conversion reactions within the field of oxides, we felt confident that solving the poor capacity retention and rate capability problems observed for $\mathrm{NiP}_{2}$ and most likely associated to the poor electronic/ionic conductivity of the formed composite electrode and hence interfacial issues was not an insurmountable task as our first approach has indicated. 


\section{Improving $\mathrm{NiP}_{2}$ electrode performance}

Such issues are quite common within the field of energy storage. For instance, to overcome the poor conductivity of the $\mathrm{Ni}(\mathrm{OOH})_{2}$ electrode used in Ni-based batteries, ${ }^{[25]}$ researchers have introduced Nifoam to either physically (immersion of the electrode with the $\mathrm{Ni}(\mathrm{OOH})_{2} /$ carbon/binder paste) or chemically (electro-deposition of $\mathrm{Ni}(\mathrm{OH})_{2}$ into the Ni-foam) host and therefore confer to the system high power rate capabilities. Within the same spirit, Brousse and co-workers have succeeded in growing $\mathrm{Cu}_{3} \mathrm{P}$ and $\mathrm{Ni}_{2} \mathrm{P}$ on $\mathrm{Cu}$ and $\mathrm{Ni}$ metallic foils, respectively. ${ }^{[26,27]}$ In this study, we have explored the growth of $\mathrm{NiP}_{2}$ onto $\mathrm{Ni}$ foam as described next.

Ni-foams purchased from RECEMAT (RCM-Ni-4852.016) were disposed in one compartment of a two-compartment evacuated and sealed quartz ampoule with, in the other compartment, stoichiometric amounts of red phosphorous powders. A survey of various temperatures (ranging from $300^{\circ} \mathrm{C}$ to $700^{\circ} \mathrm{C}$ ) and reaction times ( 2 to 120 hours) was conducted. The quartz vessels were placed into an oven and once the selected annealing temperature profile completed, the oven was turned off, the tube opened and the Ni grid recovered for X-ray analysis and both SEM and EDS characterization. High temperature treatments $\left(650^{\circ} \mathrm{C}\right)$ gave the monoclinic $\mathrm{NiP}_{2}(\mathrm{a}=6.38 \AA \mathrm{b}=5.62 \AA \mathrm{c}=6.08 \AA, \beta=126.22, \mathrm{C} 2 / \mathrm{c})$ but the Ni-foam was fully consumed losing its mechanical integrity. In contrast, we experienced that for annealing temperatures lower than $300^{\circ} \mathrm{C}$ we could not obtain the $\mathrm{NiP}_{2}$ phase independently of the reacting time. Thus, in order to tune the thickness of the grown $\mathrm{NiP}_{2}$ phase to that of $\mathrm{Ni}$, we fixed the annealing temperature at $350^{\circ} \mathrm{C}$ and varied the reacting time from 2 to 120 hours. The $\mathrm{NiP}_{2}$ monoclinic phase formed (Fig. 15) with times greater than two hours (as deduced by XRD) and the $\mathrm{NiP}_{2}$ thickness layer (as deduced by SEM, Fig 15 b) increased with time to reach values of 3-4 $\mu$ m after 6 hours, 7-20 $\mu \mathrm{m}$ after 12 hours and exceeding $20 \mu \mathrm{m}$ for longer times. An example of SEM observation of a treated Ni-foam (Fig. 15 b) clearly shows the growth of porous and flaky $\mathrm{NiP}_{2}$ layers from metallic nickel 
indicative of a good chemical interface. The film surface presents a layered crystallized morphology (Fig. 15b). The heat-treated foams were electrochemically tested in Li-half cells. The best performances were obtained for those treated at $350^{\circ} \mathrm{C}$ for 6 and 12 hours with namely the reversible insertion of 5.4 and 5.2 $\mathrm{Li}$ per $\mathrm{NiP}_{2}$, respectively. Therefore, the most important finding lies in the capacity retention of such electrodes, which outperforms what has been achieved so far from classical electrode preparation (Fig. 16). Once the first cycle is achieved, note that the $\mathrm{NiP}_{2}$ loaded Ni-foam sustained more than $90 \%$ of its capacity after 10 cycles (Fig.16 inset left), slightly better than the powder (Fig.3). Besides, such electrodes also show better rate capabilities since they can deliver $92 \%$ of their initial capacity at a C rate (Fig. 16 inset right).

Needless to say that further optimization work remains to be done, therefore such results are very encouraging and help in building confidence in the possible use of phosphides in the next generation of Li-ion cells.

\section{Conclusions}

We have reported the electrochemical reactivity of two $\mathrm{NiP}_{2}$ polymorphs (cubic and monoclinic) towards $\mathrm{Li}$. The monoclinic form turns-out to exhibit the largest capacity since it reversibly reacts with 5.0 Li per unit formula compared to solely 4.2 for the cubic form. Although the first discharge vs. Li of the two polymorphs was enlisting different reacting paths, it turns-out that the fully discharged material was alike composition wise and made of $\mathrm{Li}_{3} \mathrm{P}$ and Ni nanoparticles. From complementary XRD and HREM we could unambiguously deduce that on the subsequent cycles both polymorphs were reacting with $\mathrm{Li}$ according to the following conversion process $\left(\mathrm{NiP}_{2}+6 \mathrm{Li}^{+}+6 \mathrm{e}^{-} \rightarrow \mathrm{Ni}^{\circ}+2 \mathrm{Li}_{3} \mathrm{P}\right)$. To our knowledge, $\mathrm{NiP}_{2}$ is among the first phosphides so far reported to react with $\mathrm{Li}$ through a full conversion process. In comparing with other phosphides, the attractiveness of $\mathrm{NiP}_{2}$ does not lie on its large reversible capacity that is shared by other binary $\left(\mathrm{FeP}_{2}\right)$ or ternary phosphides $\left(\mathrm{Li}_{9} \mathrm{TiP}_{4}\right)^{[28]}$ but rather on its ability to sustain $90 \%$ of its capacity over 15 cycles as well as on its aptitude to deliver its full 
capacity at $0.5 \mathrm{C}$. The promises provided by this material were further exploited by confectioning a new electrode configuration within which the $\mathrm{NiP}_{2}$ phase is directly grown on a $\mathrm{Ni}$-foam. Using such trick we could obtain carbon-free self-supported nickel diphosphide electrodes capable of sustaining high capacities over many cycles while having enhanced rate capabilities. We hope that this new electrode design approach will help to pave the way towards the optimization of binary phosphides such as $\mathrm{FeP}_{2}$, that were abandoned despite their large initial capacity, because of a very poor capacity retention. However, it should be noted that although the elaboration of electrodes marrying chemically the current collector $(\mathrm{Ni})$ and the active material $\left(\mathrm{NiP}_{2}\right)$ did improve the capacity retention, they are still space for improvement. We believe, that further work needs to be done at the electrolyte level aiming towards a better understanding of the secondary reactions linked to the electrolyte compatibility with phosphorous-based electrode materials. Implementation of this work towards the elaboration of other self-supported binary phosphides electrodes and their behaviour in various classes of electrolytes is presently being conducted. 


\section{References}

1) Huggins, R.A.; J. Power Sources 1999, 13, 81.

2) Besenhard, J.O.; Yang J.; Winter, M. J. Power Sources 1997, 68, 87.

3) Kushida, K.; Kuriyama, K.; Nozaki, T. Applied Physics Letters 2002, 81(26), 5068.

4) Sony Corp. Info, 15 February 2005 : http://www.sony.net/SonyInfo/News/Press/

5) Poizot, P. ; Laruelle, S. ; Grugeon, S. ; Dupont L. ; Tarascon, J.-M. Nature, 2000, 407, 496.

6) Grugeon, S.; Laruelle, S.; Dupont, L.; Tarascon, J.-M. Solid State Sciences 2003, 5, 895.

7) Débart, A. ; Dupont L. ; Patrice R. ; Tarascon J-M., J. of Materials Chemistry (submitted)

8) Badway F.; Cosandey F.; Pereira N.; Amatucci G.G.; J. Electrochem. Soc., 2003, 150, A1318A1327.

9) Gillot, F. ; Monconduit, L.; Morcrette, M.; Doublet, M-L.; Tarascon, J-M. ; Chem Mat. 2005, 17, 3627.

10) Hu J.; Li H.; Huang X., Electrochem. Solid-State Lett., 2005, 8, A66

11) Pralong, V.; Leriche, J.-B.; Beaudoin, B.; Naudin, E.; Morcrette, M.; Tarascon, J.-M Solid State Ionics 2004, 166(3), 295.

12) Tarascon J-M. ; Grugeon S. ; Laruelle S. ; Larcher D. ; Poizot P. Book chapter in "Science and Technology of Advanced Lithium Batteries" (2003). Lithium Batteries - Science and Technology, ed. G.A.Nazri \& G. Pistoia, Kluwer Academic Publishers, Boston (2003).

13) Silva, D.C.C.; Crosnier, O.; Ouvrard, G.; Greedan, J.; Safa-Sefat, A.; Nazar, L; Electrochem. Solid State Lett., 2003, 6, A162. 
14) Alcantara, R.; Tirado, J.L.; Jumas, J.C.; Monconduit, L.; Olivier-Fourcade, J., J. Power Sources 2002, 109, 308. Pralong, V.; Souza, D.C.S.; Leung, K. T.; Nazar, L.; Electrochem. Comm., 2002, 4(6), 516.

15) Woo, S.; Sohn, H.-J.; Abs. 264, IMLB 12 Meeting, The Electrochem. Soc., 2004.

16) Orsini, F; Du Pasquier, A ; Beaudoin, B; Tarascon, J-M ; Trentin, M ; De Beer, E ; Notten, P ; J. Power Sources 1998, 76, 19.

17) Ren, J.; Liang, W.; Whangbo, M.-H. Crystal and Electronic Structure Analysis Using CAESAR (1998) http://www.primeC.com

18) Kresser, G.; Hafner, J. Phys. Rev. B 1993, 47, 558.

19) Rundqvist, S. Acta Chem. Scand., 1961, 15, 451.

20) Donohue, P. C.; Bither, T. A.; Young, H. S. Inorg. Chem. 1968 , 7, 998.

21) Takacs, L.; Mandal, S. K.; Materials Science and Engineering, 2001, 429, A 304.

22) Shirotani, I.; Takahashi, E.; Mukai, N.; Nozawa, K.; Kinoshita, M.; Yagi, T.; Suzuki, K.; Enoki, T.; Hino, S. Japanese Journal of Applied Physics, 1993, 1, 32.

23) Brauer, G.; Zintl, E. Z. Physik Chem. Abt. 1937, B37, 323.

24) Maier, J.;"Nano-Ionics": Ion Transport and Electrochemical Storage in Confined Systems Nature Materials, submitted, 2005.

25) Ho, K. C. ; Jerne, J.; Electrochem. Eng. App., 1987, 83, 254.

26) Pfeiffer, H ; Tancret, F ; Bichat, M-P ; Monconduit, L; Favier, F ; Brousse, T ; Electrochem. comm. 2004, 6, 3 , 263.

27) Pfeiffer, H.; Tancret, F.; Brousse.,T; Mat.Chem.and Physics 2005, 92, 534. 
28) Gillot, F. ;Bichat, M.P.; Favier, F ; Morcrette, M.; Doublet, M-L.; Monconduit, L.; Electrochim. Acta. 2004, 49, 2325. Bichat, M.P. ; Gillot, F. ; Monconduit, L.; Favier, F ; Morcrette, M ; Lemoigno, F. ; Doublet, M-L.; Chem. Mat.. 2004, 16, 1002. 


\section{FIGURES CAPTIONS}

Figure 1: X-ray diffraction patterns $\left(\mathrm{CuK} \alpha_{1}\right)$ of monoclinic $\mathrm{NiP}_{2}$ prepared by a high temperature ceramic route. Insets (a and b) show the SEM image and the $\mathrm{NiP}_{2}$ monoclinic structure .

Figure 2: X-ray diffraction patterns $\left(\mathrm{CuK} \alpha_{1}\right)$ of cubic $\mathrm{NiP}_{2}$ prepared by ball-milling route. Insets (a and b) show the $\mathrm{SEM}$ image andthe $\mathrm{NiP}_{2}$ cubic structure .

Figure 3: The voltage-composition traces for a $\mathrm{HT}-\mathrm{NiP}_{2} / \mathrm{Li}$ cell cycled at a $\mathrm{C} / 10$ rate between 2 to $0 \mathrm{~V}$ is shown together with as inset its capacity retention.

Figure 4: Voltage-composition curve for a $\mathrm{Li}$ half-cell, using a $\mathrm{BM}-\mathrm{NiP}_{2}$ sample as the positive electrodes, and cycled between 2.5 to $0.1 \mathrm{~V}$ at a $\mathrm{C} / 10$ rate. The inset shows the capacity retention at two different regime $\mathrm{C} / 10$ and $\mathrm{C} / 20$.

Figure 5: In situ X-ray diffraction patterns collected during the discharge of a $\mathrm{NiP}_{2}-\mathrm{HT} / \mathrm{Li}$ electrochemical cell down to $0.02 \mathrm{~V}$ at a $\mathrm{C} / 10$ rate (see inset). Bragg reflections are indexed for the mother phase, and the Bragg peaks corresponding to the A-phase (see text) and $\mathrm{Li}_{3} \mathrm{P}$ phase are referred by stars and empty cycles, respectively. 
Figure 6: In situ X-ray diffraction patterns collected at various stages of discharge of a $\mathrm{NiP}_{2}-\mathrm{BM} / \mathrm{Li}$ electrochemical cell cycled between 0.01 and $2.5 \mathrm{~V}$ at a C/10 rate. Empty circles show the Bragg peaks corresponding to $\mathrm{Li}_{3} \mathrm{P}$ phase hkl's were used to represent the Bragg peaks corresponding to the $\mathrm{NiP}_{2}-$ BM phase (bottom) and to $\mathrm{Li}_{3} \mathrm{P}$ (top).

Figure 7: In situ X-ray diffraction patterns collected at various stages of charge of a $\mathrm{NiP}_{2}-\mathrm{BM} / \mathrm{Li}$ electrochemical cell (a) cycled between 0.01 and $2.5 \mathrm{~V}$ at a $\mathrm{C} / 10$ rate and of second discharge of the same electrochemical cell (b).

Figure 8: HRTEM image realized on the edge of a monoclinic $\mathrm{NiP}_{2}$ particle (right inset) along the 001 zone axis according to the electron diffraction pattern (left inset).

Figure 9: $\quad$ TEM study of partially discharged monoclinic $\mathrm{NiP}_{2}$ of $" \mathrm{Li}_{2.4} \mathrm{NiP}_{2}$ " composition. a)Highresolution image showing random intergrowth of disordered domains, b) Corresponding SAED pattern, along the 010 zone axis, c) Scheme showing the reciprocal space reconstruction (Experimental dots are in green(plain) while extrapolated ones are open in blue), d) SAED pattern along the 1-30 zone axis.

Figure 10: Structural rearrangements involved in the $\mathrm{NiP}_{2}$ monoclinic structure in the inter-layers (a) and in the layer (b) planes to form the $\mathrm{Li}_{\mathrm{x}} \mathrm{NiP}_{2}$ tetragonal phase (Black circles represent the Ni atoms and small gray circles represent the P atoms). The Extended Huckel Tight-Binding (EHTB) electronic structure are shown for $\mathrm{NiP}_{4}$ (square plane) (c) and $\mathrm{NiP}_{6}$ (oactahedra) -type environments (d). 
Figure 11: Bright Field TEM image showing the alternation of collapsed domains (dark arrows) with layered A-phase domains. Inset: enlarged image showing the formation of nano-particles at the edge of the domains.

Figure 12: Bright field images recorded on a fully discharged monoclinic $\mathrm{NiP}_{2}-\mathrm{HT}$ sample. The $\mathrm{a}$ and $\mathrm{b}$ sequence corresponds to an increase in magnification as well as beam exposure time. a) Dark arrow on the inset shows the polymeric layer vanishing under the beam then continuous disappearing of $\mathrm{Li}_{3} \mathrm{P} /$ polymeric layer is observed, b) high resolution image of nickel nanoparticles together with a FTT in inset.

Figure 13: $\quad$ TEM images recorded on a fully recharged monoclinic $\mathrm{NiP}_{2}-\mathrm{HT}$ sample up to $2 \mathrm{~V}$. a) Some agglomerates are still surrounded by a thick polymeric coating. b) enlarged image, c) highresolution image, and d) high resolution image of monoclinic $\mathrm{NiP}_{2}$ together with a FTT in inset.

Figure 14: The derivatives $\mathrm{dx} / \mathrm{dV}$ plots are shown for the fifth cycle for two $\mathrm{BM}-\mathrm{NiP}_{2} / \mathrm{Li}$ and HT$\mathrm{NiP}_{2} / \mathrm{Li}$ cells cycled at a $\mathrm{C} / 10$ rate between 2 and $0.01 \mathrm{~V}$.

Figure 15: SEM images of a Ni-foam reacted with $\mathrm{P}$, according to the conditions described in the text $\left(12 \mathrm{~h}, 350^{\circ} \mathrm{C}\right)$, are shown. In a) the pores of the $\mathrm{Ni}$ foam recovered by $\mathrm{NiP}_{2}$ are shown. b) enlarged image 
nicely showing the growth of the $\mathrm{NiP}_{2}$ phase until the $\mathrm{Ni}$ current collector, as deduced by the corresponding EDX analysis and nano-sheet morphology of the obtained $\mathrm{NiP}_{2}$.

Figure 16: Composition voltage curve for the foam- $\mathrm{NiP}_{2} / \mathrm{Li}$ cell at $\mathrm{C} / 10$ from 2 to $0 \mathrm{~V}$ at a $\mathrm{C} / 2$ rate with as inset (a) its corresponding capacity retention. The second inset (b) shows the rate capability performance of a foam- $\mathrm{NiP}_{2}$ electrode measured, for reasons of current density associated to Li metal, in a Li-ion-type configuration using $\mathrm{LiFePO}_{4}$ as the positive electrode. 


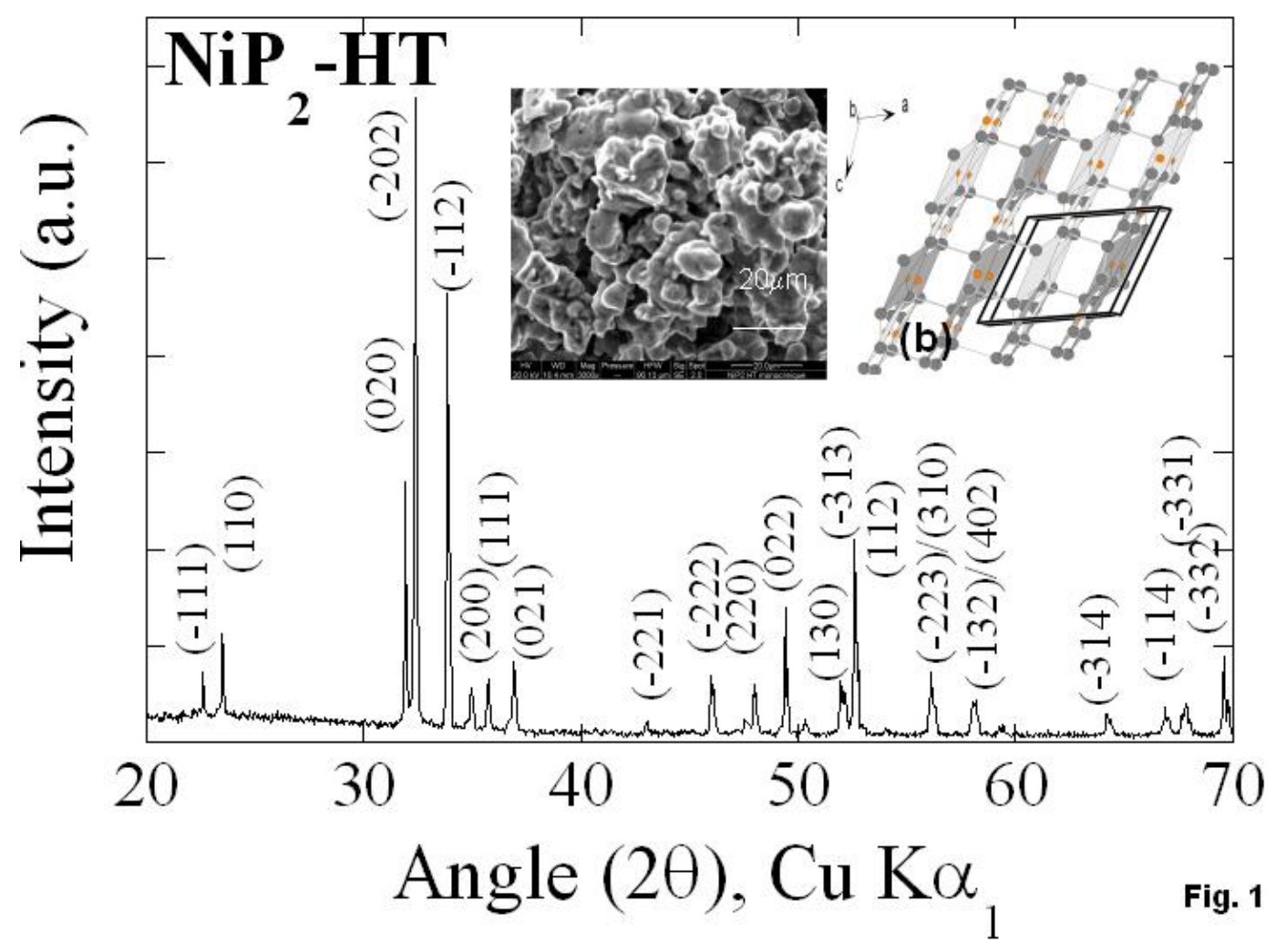




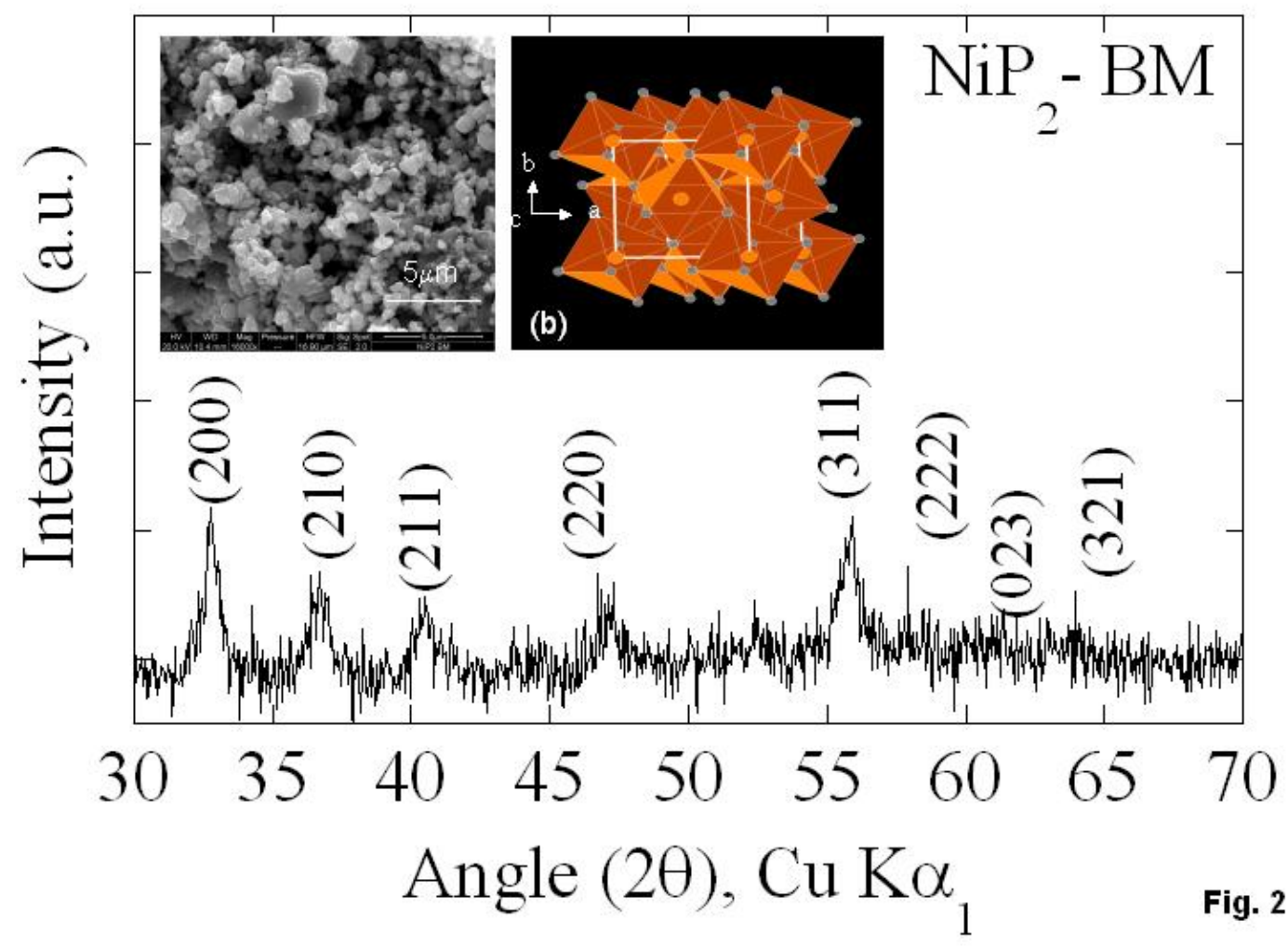

Fig. 1 
Capacity $(\mathrm{mAh} / \mathrm{g})$

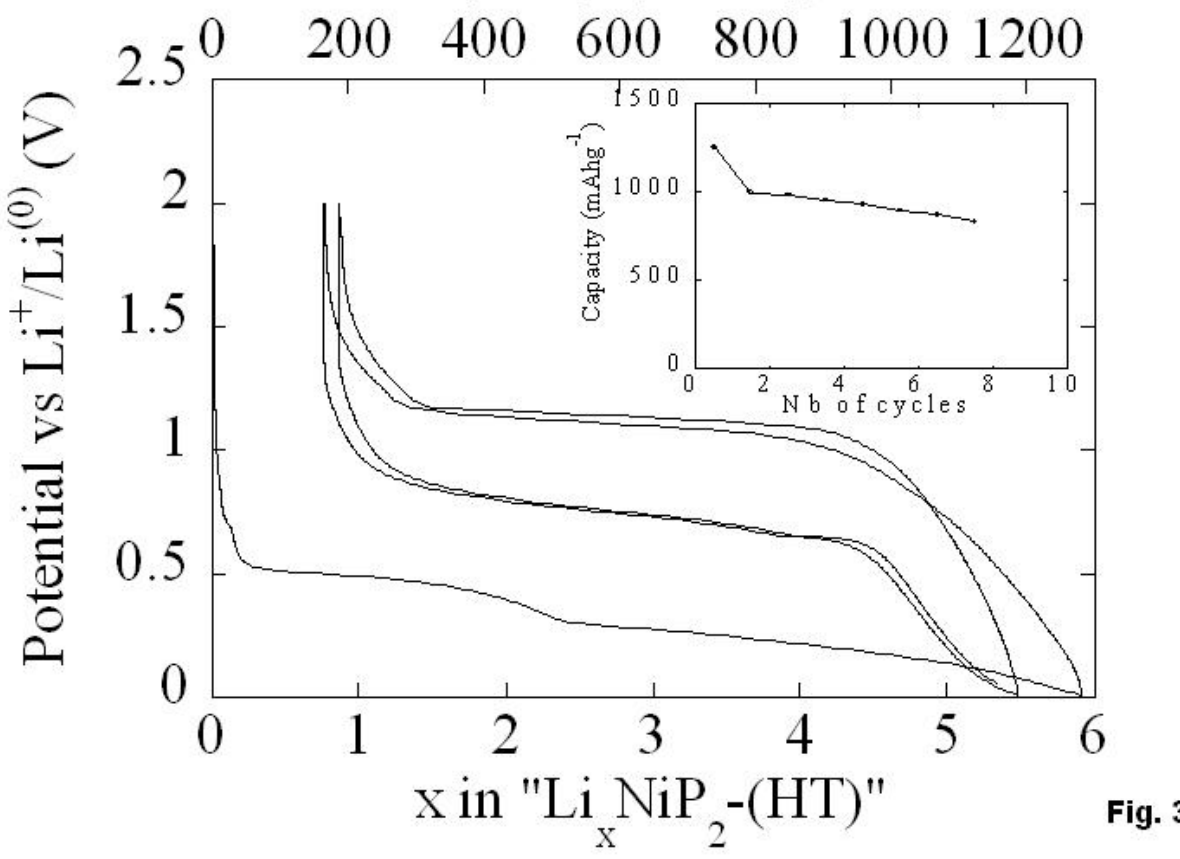




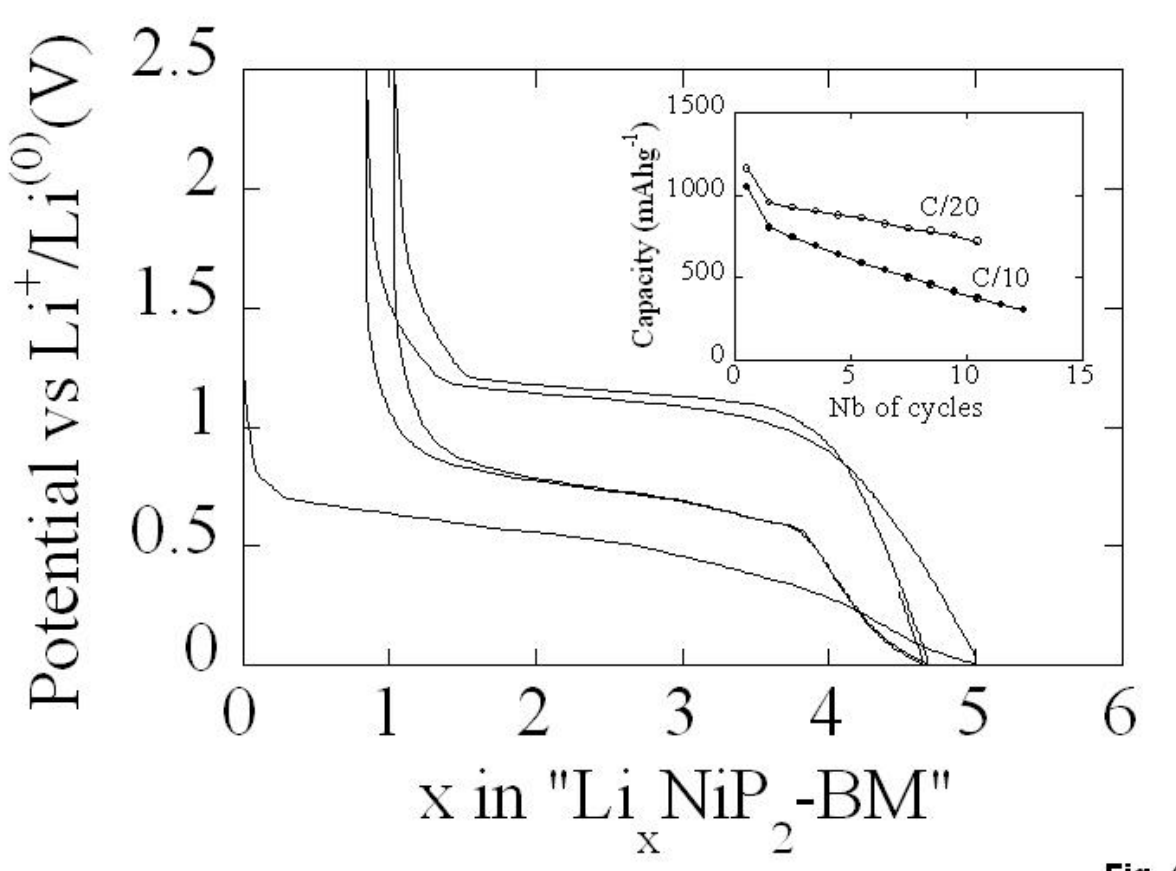

Fig. 4 


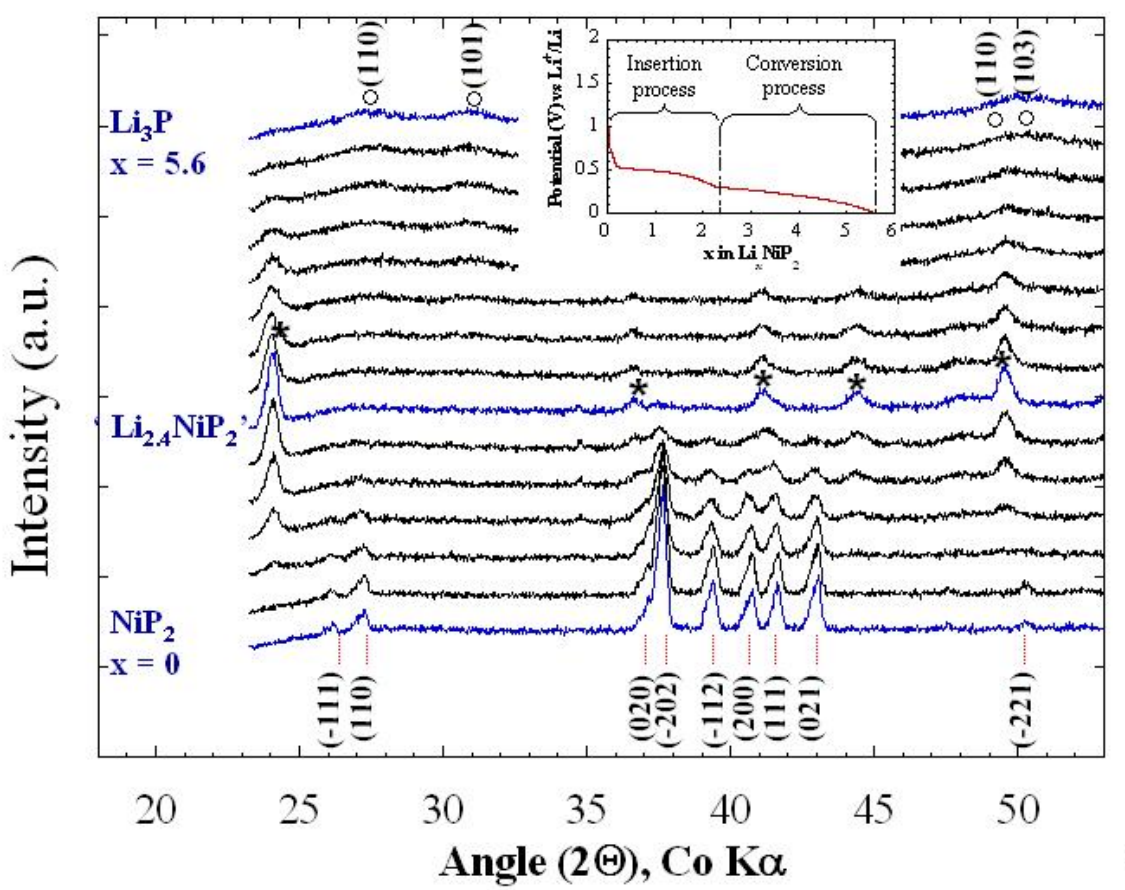

Fig. 5 


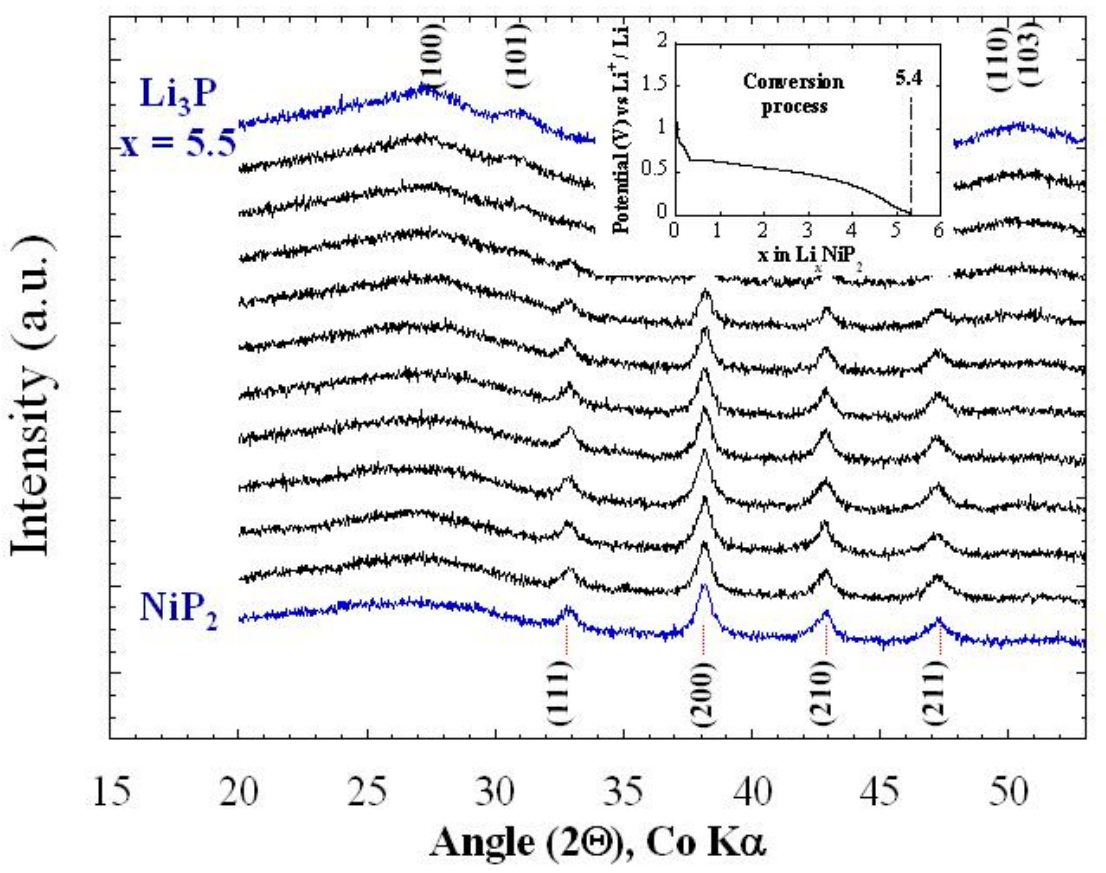

Fig. 6 

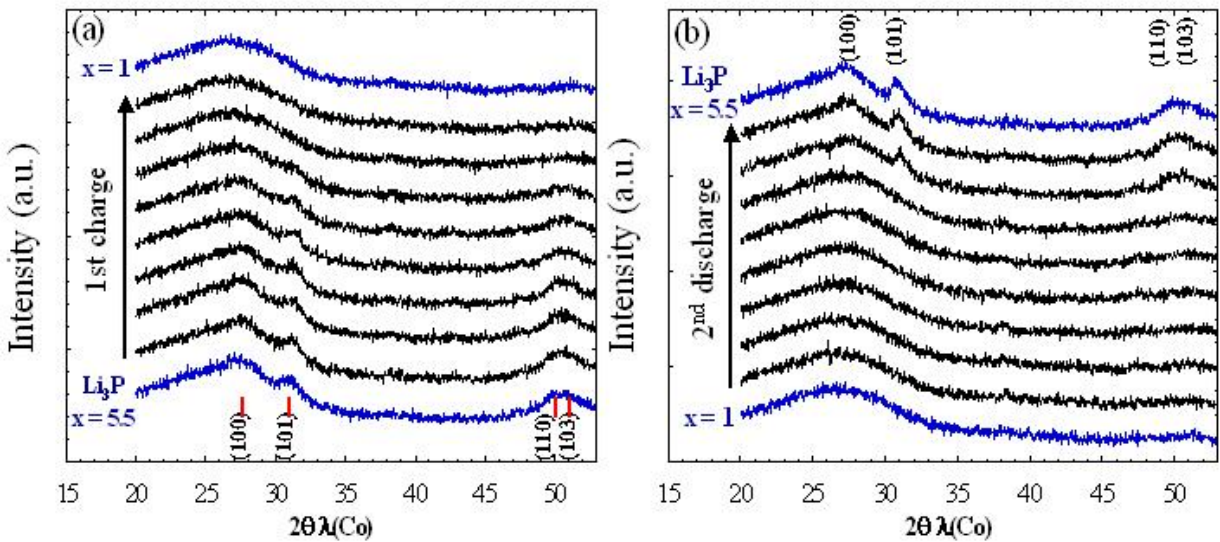

Fig. 7 


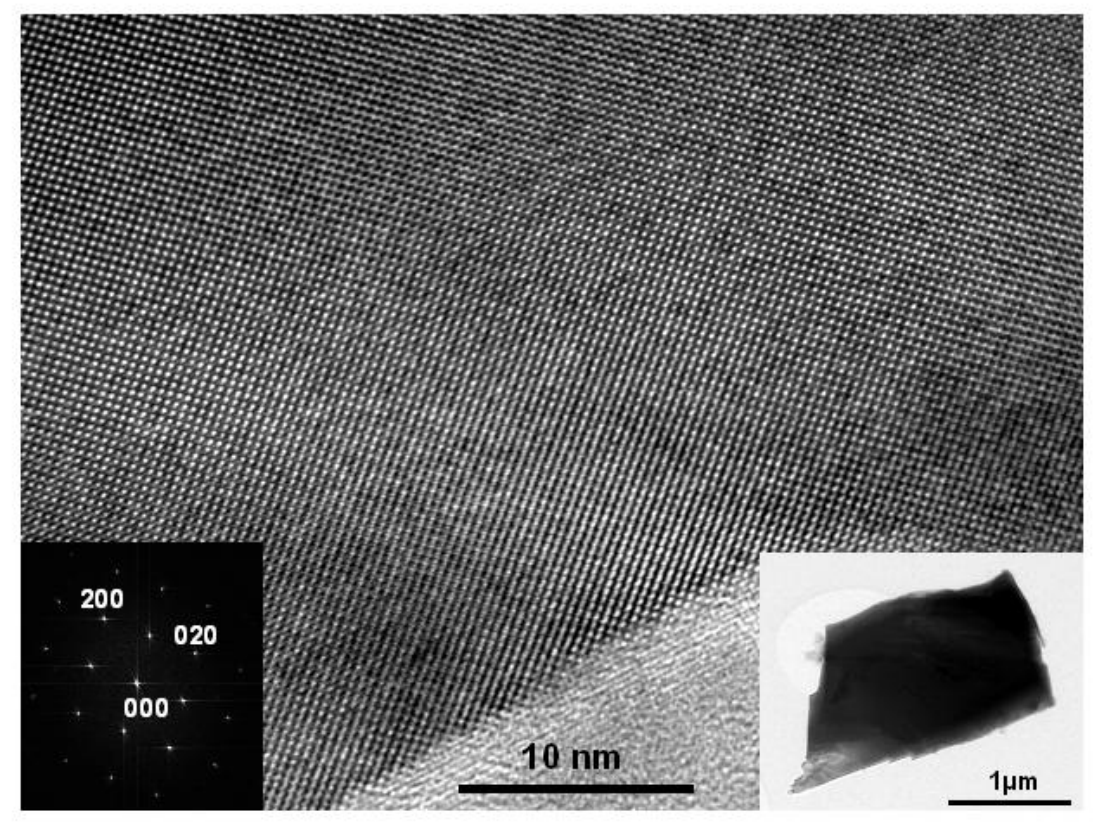

Fig. 8 


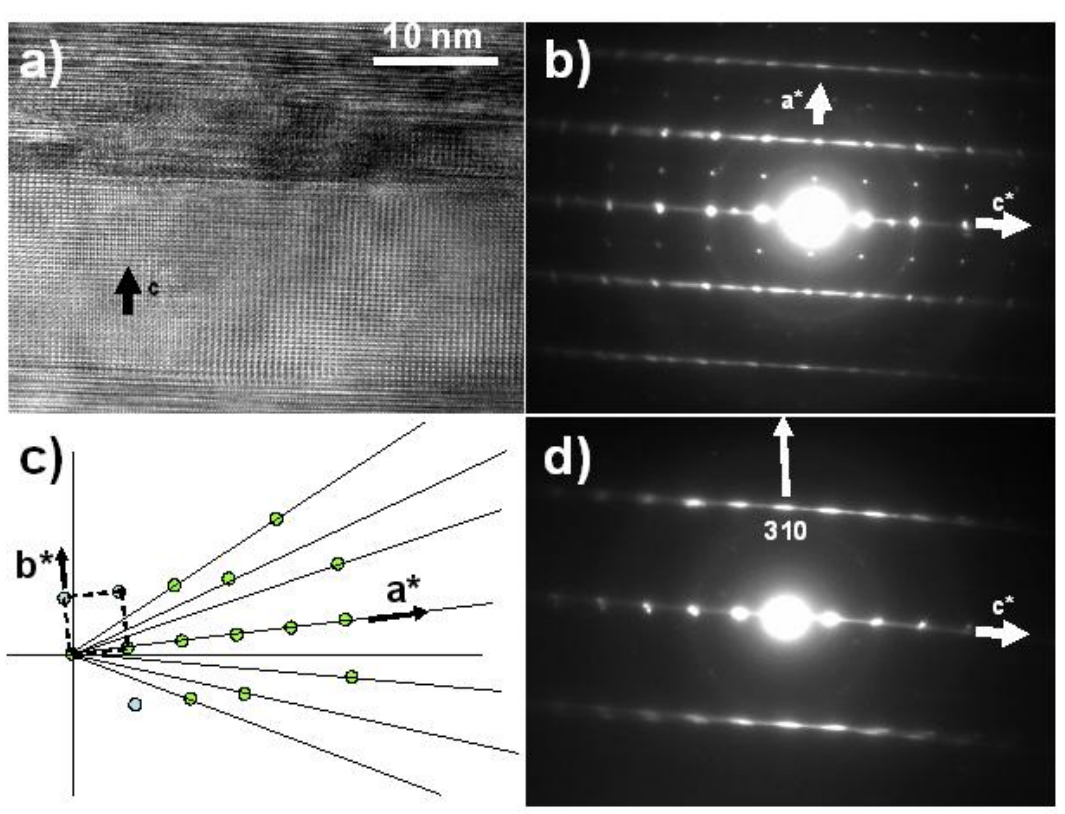

Fig. 9 

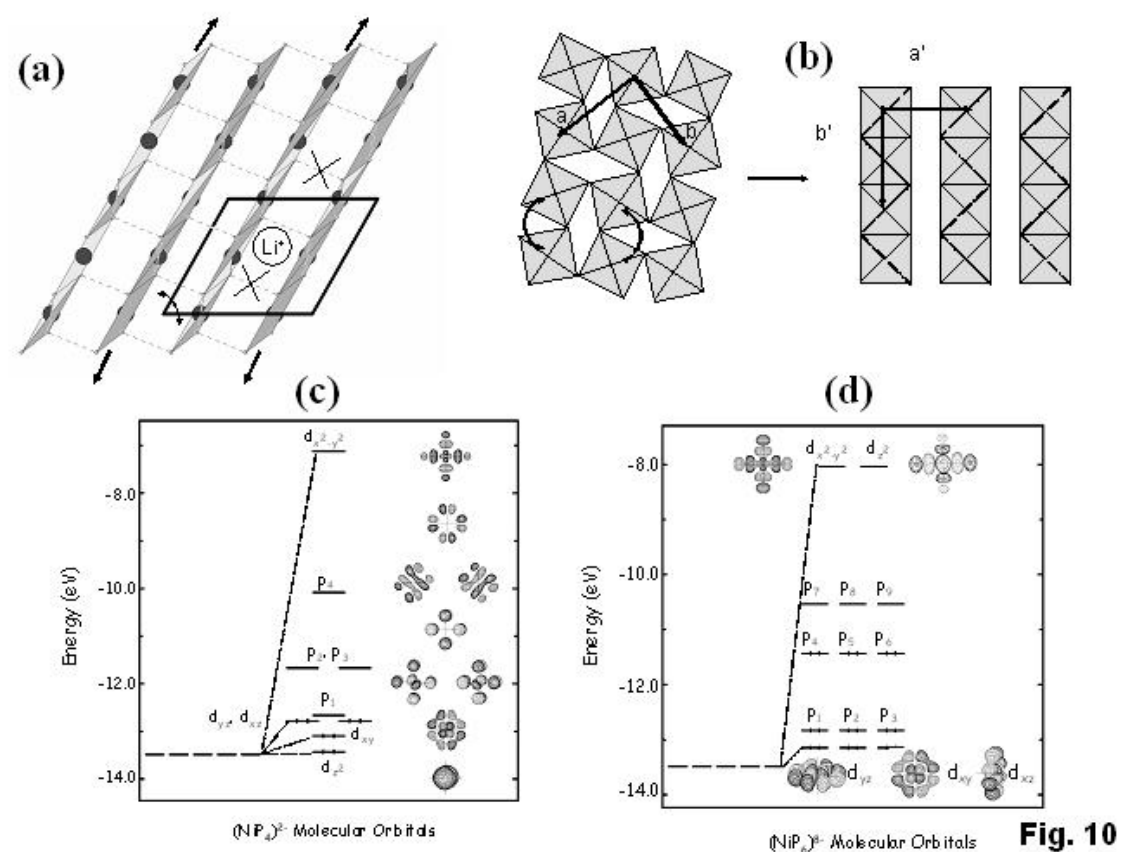


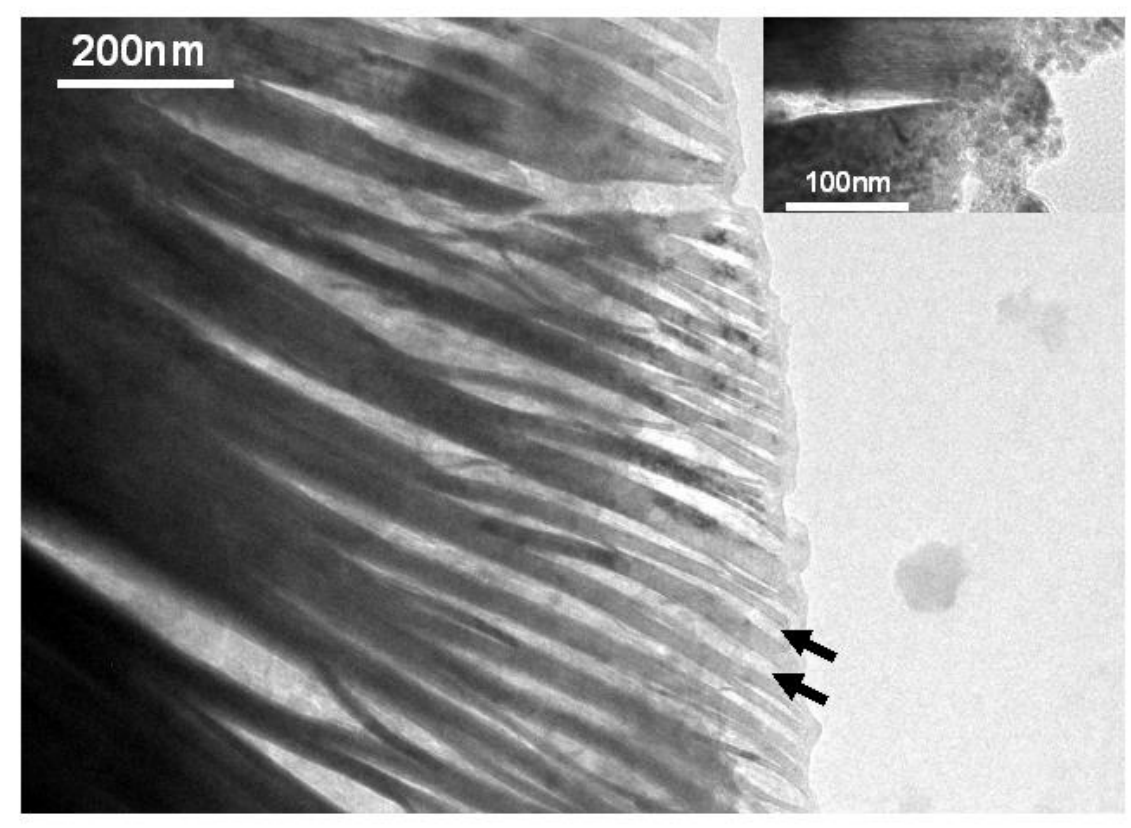

Fig. 11 

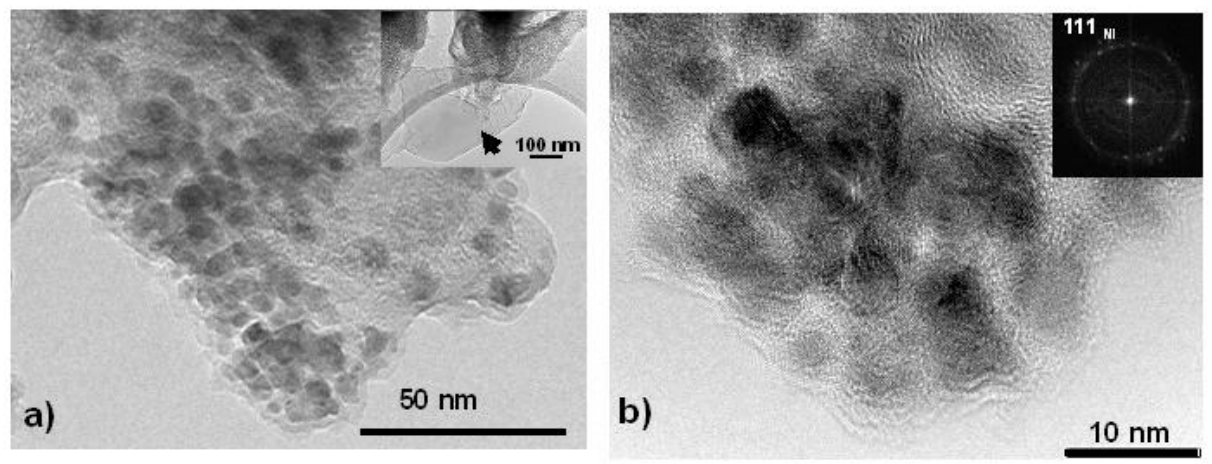

Fig. 12 


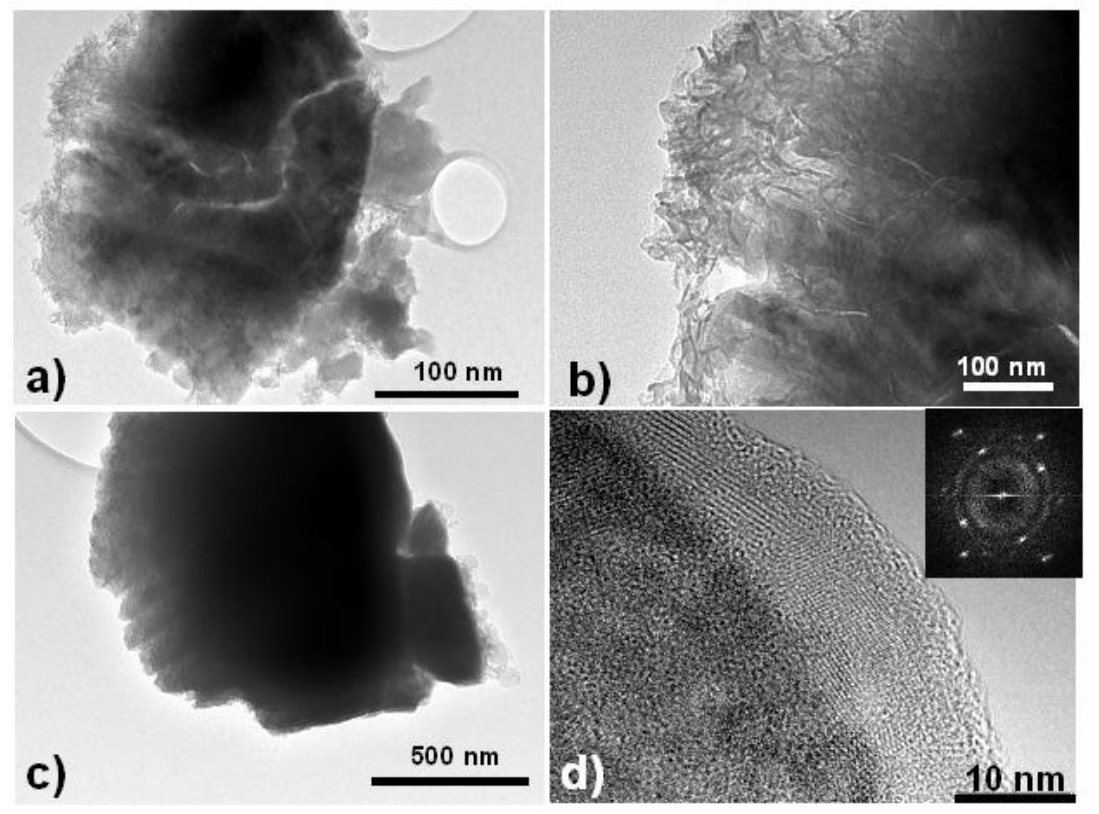

Fig. 13 


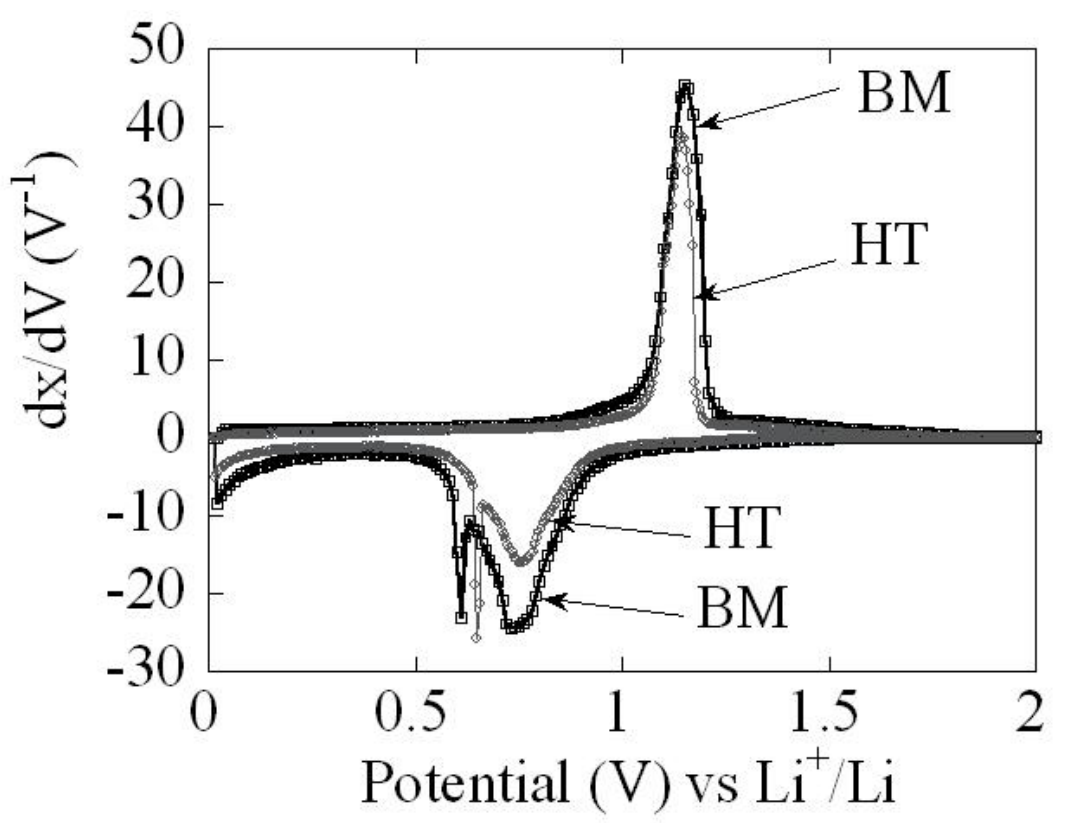

Fig. 14

Fig. 15 


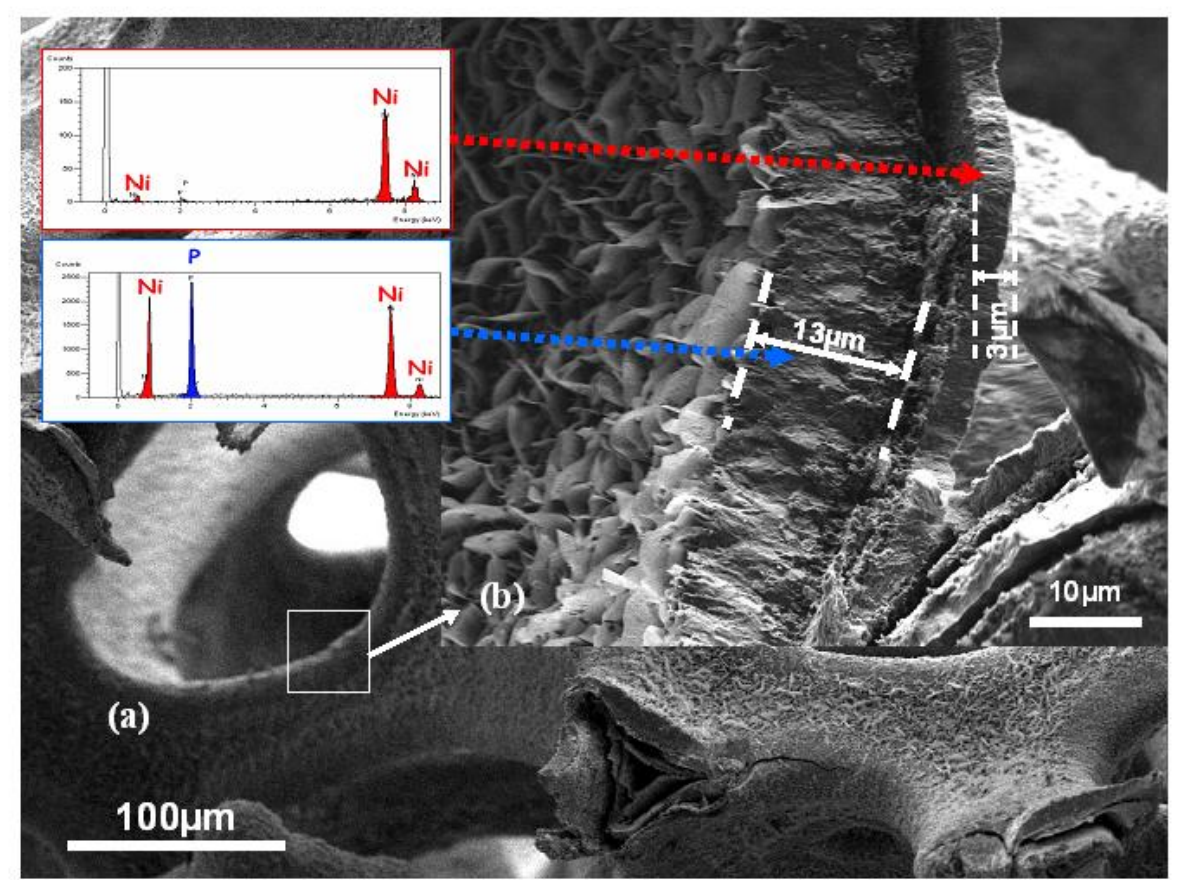

Fig. 15,

Mis en forme 


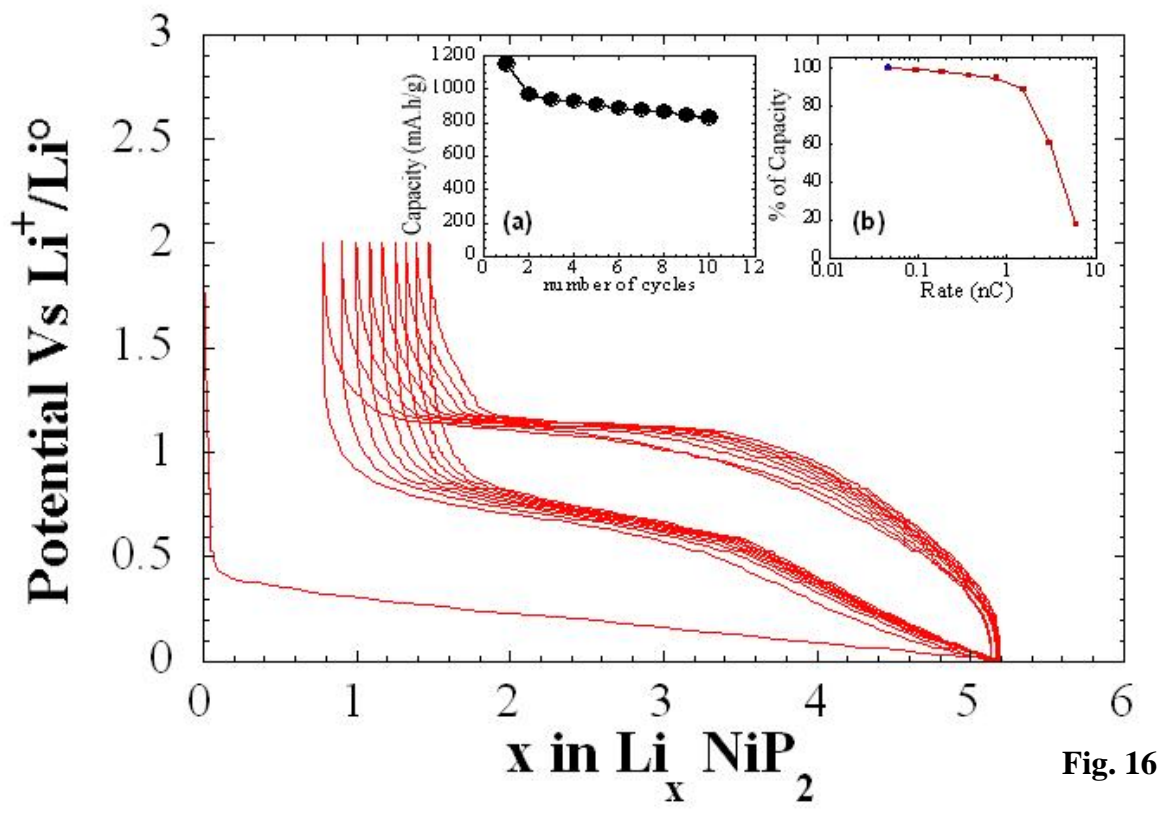

Mis en forme 